\title{
Targeting biofilms and persisters of ESKAPE pathogens with P14KanS, a kanamycin peptide conjugate
}

\author{
Mohamed F. Mohamed ${ }^{1}$, Anna Brezden ${ }^{2}$, Haroon Mohammad ${ }^{1}$, Jean Chmielewski ${ }^{2,3}$, \\ Mohamed N. Seleem ${ }^{1,3 *}$ \\ ${ }^{1}$ Department of Comparative Pathobiology, Purdue University, West Lafayette, IN, 47907-2027, \\ (USA) ${ }^{2}$ Department of Chemistry, Purdue University, West Lafayette, IN 47907-2084, (USA) \\ ${ }^{1,3}$ Purdue Institute for Inflammation, Immunology, and Infectious Disease, Purdue University, \\ West Lafayette, IN 47907, USA.
}

Running title: Targeting bacterial biofilms with P14KanS

Key words: Biofilm, persisters, antimicrobial peptides, kanamycin, ESKAPE, and antiinflammatory.

\section{*Corresponding Author:}

Mohamed N. Seleem

Department of Comparative Pathobiology

Purdue University College of Veterinary Medicine

625 Harrison Street, Lynn 1298, West Lafayette, IN 47907-2027

Phone: 765-494-0763 Fax: 765-496-2627

Email:mseleem@purdue.edu 


\section{$\underline{\text { Abstract: }}$}

Background: The worldwide emergence of antibiotic resistance represents a serious medical threat. The ability of these resistant pathogens to form biofilms that are highly tolerant to antibiotics further aggravates the situation and leads to recurring infections. Thus, new therapeutic approaches that adopt novel mechanisms of action are urgently needed. To address this significant problem, we conjugated the antibiotic kanamycin with a novel antimicrobial peptide (P14LRR) to develop a kanamycin peptide conjugate (P14KanS).

Methods: Antibacterial activities were evaluated in vitro and in vivo using a Caenorhabditis elegans model. Additionally, the mechanism of action, antibiofilm activity and antiinflammatory effect of P14KanS were investigated.

Results: P14KanS exhibited potent antimicrobial activity against ESKAPE pathogens. P14KanS demonstrated a $\geq 128$-fold improvement in MIC relative to kanamycin against kanamycinresistant strains. Mechanistic studies confirmed that P14KanS exerts its antibacterial effect by selectively disrupting the bacterial cell membrane. Unlike many antibiotics, P14KanS demonstrated rapid bactericidal activity against stationary phases of both Gram-positive and Gram-negative pathogens. Moreover, P14KanS was superior in disrupting adherent bacterial biofilms and in killing intracellular pathogens as compared to conventional antibiotics. Furthermore, P14KanS demonstrated potent anti-inflammatory activity via the suppression of LPS-induced proinflammatory cytokines. Finally, P14KanS protected C. elegans from lethal infections of both Gram-positive and Gram-negative pathogens.

Conclusions: The potent in vitro and in vivo activity of P14KanS warrants further investigation as a potential therapeutic agent for bacterial infections. 
General significance: This study demonstrates that equipping kanamycin with an antimicrobial peptide is a promising method to tackle bacterial biofilms and address bacterial resistance to aminoglycosides.

\section{Introduction}

The emergence of antibiotic resistance is a notorious problem worldwide [1]. In the United States alone, antibiotic-resistant bacteria infect at least two million people, killing 23,000 patients annually [2]. Currently, members of the ESKAPE pathogens (Enterococcus faecium, Staphylococcus aureus, Klebsiella pneumoniae, Acinetobacter baumannii, Pseudomonas aeruginosa, and Enterobacter species) represent one of the most significant threats to human health as strains exhibit resistance to multiple antibiotic classes[3]. Compounding the situation further, global reports of extensively drug-resistant (XDR) and pandrug-resistant (PDR) isolates of P. aeruginosa and A. baumannii have been increasing [4-6]. The ability of these resistant pathogens to form biofilms that are highly tolerant to antibiotics further aggravates the situation, 
ultimately leading to persistent and recurring infections [7, 8]. Hence, the development of therapeutic alternatives that have novel mechanisms of action are urgently needed in order to effectively address this problem.

Aminoglycosides are a class of valuable antibiotics that are used in the treatment of several microbial infections [9-11]. They bind to the 16S rRNA component of the bacterial ribosome, leading to mistranslation and bacterial death. However, the worldwide epidemic of resistance to aminoglycosides, to kanamycin in particular, has diminished their widespread clinical use [9-12].

We recently conjugated kanamycin with the antibacterial peptide P14LRR to achieve a dual agent (P14KanS) (Fig. 1). P14LRR is a small de novo proline rich antimicrobial peptide that forms a cationic amphiphilic polyproline helix and demonstrates broad-spectrum efficacy against pathogenic bacteria $[13,14]$. P14LRR is non-hemolytic and highly stable to proteases. These characteristics contributed to the selection of P14LRR for conjugation to kanamycin. However, much remains to be examined with P14KanS including its spectrum of activity against Grampositive and Gram-negative pathogens, its mechanism of action, its ability to disrupt bacterial biofilms, its efficacy against stationary phase bacteria, and confirming its potent antibacterial activity in a suitable animal model of infection.

In the present study, we investigated the activity of the P14KanS conjugate against important multidrug-resistant strains of the ESKAPE family. Additionally, we explored the conjugate's mechanism of action against kanamycin-resistant isolates. Moreover, the conjugate's ability to eradicate preformed biofilms and to kill stationary phases of pathogens was examined. Furthermore, the immune-modulatory activity of the conjugate was explored. Finally, the antibacterial activity of the conjugate was validated in vivo using a Caenorhabditis elegans 
model of bacterial infection. Taken altogether, our findings indicate that the conjugate is a promising candidate that warrants further investigation as a therapeutic agent for multidrugresistant bacterial pathogens.

\section{Materials and methods}

\subsection{Bacterial isolates, drugs and reagents}

Clinical isolates used in the study are presented in Table 1. P14LRR peptide and the peptide kanamycin conjugate (P14KanS) (Fig. 1) were synthesized as described previously [13, 14]. Melittin was purchased from Sigma-Aldrich (St. Louis, MO). Antibiotics were purchased from commercial vendors. Mueller-Hinton broth (MHB), Dulbecco's phosphate buffered saline (PBS), fetal bovine serum (FBS), and Dulbecco's Modified Eagle's medium (DMEM) were purchased from Sigma-Aldrich (St. Louis, MO). MTS reagent was purchased from Promega (Madison, WI, USA). Brain heart infusion broth (BHIB), Trypticase soy broth (TSB) and Trypticase soy agar (TSA) were purchased from Becton-Dickinson (Cockeysville, MD). Enzyme-linked immunosorbent assay (ELISA) development kits for cytokine detection were purchased from R\&D Systems, Inc. (Minneapolis, MN).

\subsection{Determination of minimum inhibitory concentration (MIC) values}

The broth microdilution technique was utilized to assess the minimum inhibitory concentration of compounds according to the guidelines of the Clinical and Laboratory Standards Institute (CLSI)[15]. Bacterial isolates were diluted to $5 \times 10^{5}$ colony forming units (CFU/ml) in MHB (except E. faecium, diluted in BHIB). Compounds were added to 96-well plates at 
specified concentrations and subsequently serially diluted. The MIC was defined as the lowest concentration of compound that prevented visual bacterial growth.

\subsection{Mechanism of action studies}

\section{3.a Outer membrane permeabilization assay}

Permeation of the bacterial outer membrane by compounds was assessed using the nonpolar fluorescent dye 1-N-phenylnaphthylamine (NPN) as described elsewhere [16]. $P$. aeruginosa PAO1, in logarithmic growth phase was centrifuged for 10 minutes at $4000 \times \mathrm{g}$, washed, and adjusted to $\mathrm{OD}_{600}$ of 0.5 . A small aliquot $(100 \mu \mathrm{l})$ of bacteria was added to black wall 96-well plates. NPN was mixed with bacteria at a final concentration of $10 \mu \mathrm{M}$. Compounds were added, in triplicates, at specified concentrations. Plates were monitored using a microplate reader (Molecular Devices, Sunnyvale, CA) at excitation and emission wavelengths of $350 \mathrm{~nm}$ and $420 \mathrm{~nm}$, respectively. Data was corrected for background fluorescence and plotted as percentage \pm standard deviation. Experiments were done in triplicate and repeated twice independently.

\section{3.b Inner (cytoplasmic) membrane permeabilization assay}

Damage of the bacterial inner (cytoplasmic) membrane after exposure to compounds was evaluated using the fluorescent propidium iodide dye, as described elsewhere [17]. P. aeruginosa PAO1 in logarithmic growth phase, was centrifuged for 10 minutes at $4000 \times \mathrm{g}$, washed, and adjusted to $\mathrm{OD}_{600}$ of 0.2 . An aliquot $(100 \mu \mathrm{l})$ of bacterial suspension was added to black 96-well plates. Propidium iodide dye was added at a final concentration of $10 \mu \mathrm{M}$. Compounds were added, in triplicate, at specific concentrations. Bacteria treated with compound diluent (distilled water) served as a negative control. Plates were read using a microplate reader at excitation and 
emission wavelengths of $585 \mathrm{~nm}$ and $620 \mathrm{~nm}$, respectively. Data was corrected for background fluorescence and plotted as percentage \pm standard deviation. Experiments were done in triplicate and repeated twice independently.

\section{3.c Calcein leakage assay}

Membrane permeabilization of S. epidermidis (ATCC 35984) by the peptide kanamycin conjugate was monitored and quantified by the leakage of the preloaded fluorescent dye, calcein, as described before $[18,19]$.

\subsection{Time-kill assay against logarithmic and stationary phase bacteria}

S. aureus ATCC 6538, S. epidermidis ATCC 35984, P. aeruginosa PAO1 and A. baumannii ATCC BAA-1605 were grown in MHB with aeration at $250 \mathrm{rpm}$ at $37^{\circ} \mathrm{C}$ overnight, then diluted in fresh MHB and incubated aerobically at $37{ }^{\circ} \mathrm{C}$ until the suspension reached a logarithmic phase of growth $\left(\mathrm{OD}_{600}=0.2\right)$. Next, bacteria were diluted to $5 \times 10^{5} \mathrm{CFU} / \mathrm{ml}$ in MHB. Compounds were added at desired concentrations (10 $\mu \mathrm{M}$ for S. aureus and S. epidermidis and $20 \mu \mathrm{M}$ for $P$. aeruginosa and A. baumannii), in triplicate. Bacteria were incubated aerobically at $37{ }^{\circ} \mathrm{C}$ in a shaking incubator at $250 \mathrm{rpm}$. Aliquots at specified time points were taken, serially diluted in phosphate-buffered saline (PBS) and plated in triplicate on TSA. CFUs were counted after incubation of plates for 24 hours at $37^{\circ} \mathrm{C}$. In order to determine the kinetics of killing against stationary phase bacteria S. aureus ATCC 6538, S. epidermidis ATCC 35984, P. aeruginosa PAO1 and A. baumannii ATCC BAA-1605 were grown in MHB with aeration at $250 \mathrm{rpm}$ at $37{ }^{\circ} \mathrm{C}$ overnight. Bacteria were subsequently exposed to compounds at similar concentrations used in logarithmic phase. Aliquots were taken and plated as described above.

\subsection{Toxicity of compounds against mammalian cell lines}


Compounds were assayed for potential in vitro toxicity against human keratinocytes $(\mathrm{HaCaT})$ and HeLa cells as described before [20] with the following modifications. Cells were treated with compounds at various concentrations for 24 hours. Compounds were assayed for hemolytic activity against human red blood cells as described previously [18].

\subsection{Efficacy of compounds on bacterial biofilms}

The compounds were examined for their ability to disrupt bacterial biofilms using the microtiter dish biofilm formation assay $[18,21]$. Briefly, overnight cultures of $S$. aureus (ATCC 6538) and S. epidermidis (ATCC 35984) were diluted 1:100 in TSB supplemented with 1\% glucose. Overnight cultures of $P$. aeruginosa PAO1 and A. baumannii ATCC BAA-1605 were diluted 1:100 in M63 minimal medium supplemented with magnesium sulfate, glucose and casamino acids. Bacterial suspensions were incubated in 96 -well plates at $37{ }^{\circ} \mathrm{C}$ for 24 hours. After removing media, wells were rinsed with PBS to remove planktonic bacteria before refilling wells with fresh media. Compounds were added at specific concentrations and plates were incubated at $37{ }^{\circ} \mathrm{C}$ for 24 hours. After incubation, wells were washed and biofilms were stained with $0.5 \%$ (w/v) crystal violet for 30 minutes. The dye was solubilized with ethanol (95\%) and the biofilm mass was quantified at $\mathrm{OD}_{595}$. Experiments were done in triplicate and repeated twice independently.

\subsection{Intracellular antibacterial efficacy of compounds in human keratinocytes}

The compounds' ability to kill intracellular staphylococci was examined by infecting human keratinocytes, as described in previous studies [14, 22]. Briefly, HaCaT cells was seeded and incubated in DMEM + 10\% FBS. Following incubation, cells were infected with S. aureus (multiplicity of infection 100:1) in DMEM + 10\% FBS for two hours. After infection, the wells were washed with $200 \mu \mathrm{l}$ media containing gentamicin $(50 \mu \mathrm{g} / \mathrm{ml})$ and further incubated for 30 
minutes with gentamicin to kill any remaining extracellular bacteria. Compounds were diluted in DMEM $+10 \%$ FBS to the desired concentrations and wells were treated with $100 \mu$ l of DMEM +10 FBS containing compounds for 24 hours. Medium alone was used as a negative control. After incubation, the media was aspirated and washed twice with PBS to remove any residual test agent. Next, $100 \mu \mathrm{l}$ of PBS containing $0.01 \%$ Triton X-100 was added to lyse cells. Subsequently, bacteria were diluted and plated on TSA plates. Plates were incubated at $37{ }^{\circ} \mathrm{C}$ for 16 hours. After incubation, bacteria were enumerated and analyzed. Experiments were repeated twice independently and the average percent reduction of bacterial growth for each treatment regimen was determined.

\subsection{Lipopolysaccharides (LPS) studies}

\section{8.a Binding of compounds to LPS (LAL assay)}

In order to determine if the compounds could bind to LPS, a Limulus amoebocyte lysate (LAL) kit (Genscript, USA Inc.) was utilized as described in a previous study [23]. Compounds were dissolved in pyrogen-free water and serially diluted in the same solvent. The compounds were then incubated with one endotoxin unit (EU) of LPS at $37{ }^{\circ} \mathrm{C}$ for 30 minutes in order to permit the compounds to bind to LPS. The reaction mixture (50 $\mu \mathrm{l})$ was added to $50 \mu \mathrm{l}$ of LAL reagent, and further incubated for 10 minutes. Next, $100 \mu \mathrm{l}$ of LAL chromogenic substrate was added. The mixture was incubated at $37{ }^{\circ} \mathrm{C}$ for six minutes. Samples were measured at $\mathrm{OD}_{545}$ using a microplate reader. Colistin was used as a positive control. The binding of compounds with LPS was expressed as percent change relative to the untreated control.

\section{8.b Anti-inflammatory effect of compounds on LPS stimulated macrophages (neutralizing the effect of LPS on macrophages)}


The anti-inflammatory effect of compounds on LPS stimulated macrophages, J774A.1 cells, was cultured as described above. Next, the cells were stimulated with LPS (150 ng/ml final concentration) in the presence of $10 \mu \mathrm{M}$ of compounds. Cells that were stimulated with LPS alone and untreated cells served as controls. Cells were incubated for six hours at $37{ }^{\circ} \mathrm{C}$ and supernatants from each treatment were collected and stored at $-20{ }^{\circ} \mathrm{C}$ until use. Cytokine detection of tumor necrosis factor- $\alpha$ (TNF- $\alpha)$ and interleukin-6 (IL-6) in supernatants was done using ELISA as described before following the manufacturer's instructions [24, 25]. Cytokine levels were expressed as percent change relative to the LPS-stimulated control, using triplicate samples for each treatment condition.

\subsection{Multi-step resistance selection}

To evaluate the ability of $S$. aureus to acquire resistance to the peptide kanamycin conjugate and control antibiotics, a multi-step resistance selection experiment was employed. $S$. aureus ATCC 6538 was serially passaged in the presence of a sub-inhibitory concentration of kanamycin, P14LRR, P14KanS and three different classes of antibiotics, ampicillin, rifampicin, and ciprofloxacin for eight serial passages. The MIC was monitored daily using the broth microdilution assay. Results were presented as the change in MIC measurement observed after each passage in comparison to the initial MIC value.

\subsection{In vivo efficacy of compounds in a C. elegans infection model}

Infection and treatment of C. elegans was done as described previously with the following modifications [26, 27]. C. elegans AU37 [sek-1(km4); glp-4(bn2) I] was used to test the efficacy of peptides in vivo. This strain has a mutation in the sek-1 gene of the p38 mitogenactivated protein kinase pathway (p38 MAPK pathway) that makes this particular strain more susceptible to bacterial infection [26, 27]. Briefly, synchronized adult worms were transferred to 
modified NGM (0.35\% peptone) agar plates seeded with a lawn of $P$. aeruginosa PAO1, $A$. baumannii ATCC BAA-1605, S. aureus ATCC 6538 or S. epidermidis ATCC 35984 for infection. After infection, worms were collected and washed with PBS three times. Worms ( 30 per sample) were transferred to 96-well plates. Compounds were added at desired concentrations (10 $\mu \mathrm{M}$ for $S$. aureus and S. epidermidis and $50 \mu \mathrm{M}$ for P. aeruginosa and A. baumannii), in triplicate. Untreated worms served as a negative control. To assess the survival of infected $C$. elegans, worms were assessed for viability (live worms are sinusoidal with movement, whereas dead worms are rigid rods).

\subsection{Statistical analyses}

Statistical analyses were performed using GraphPad Prism 6.0 software (GraphPad Software, La Jolla, CA, USA). Comparison between two groups was analyzed using two-tailed unpaired Student t-tests. Comparison between three or more groups was analyzed using one-way ANOVA, with post hoc Tukey's multiple comparisons test. $P$-values of $<0.05$ were considered significant.

\section{Results and discussion}

\subsection{Antimicrobial activity}

The antibacterial activity of kanamycin and the conjugate was investigated against ESKAPE pathogens. The peptide, P14LRR, alone displayed moderate to weak antibacterial activity against ESKAPE pathogens with MIC values ranging from 8 to $64 \mu \mathrm{M}$ (Table 1). Kanamycin was only active against two strains (S. aureus ATCC 6538 and MRSA USA400). However, other bacteria were resistant to kanamycin (MIC, 128 to >256 $\mu \mathrm{M})$. P14KanS demonstrated a very potent, broad-spectrum antibacterial activity over kanamycin and the peptide (P14LRR). The MIC of P14KanS was 1 to $2 \mu \mathrm{M}$ against all strains tested. This 
represents a 2-4 fold improvement in the MIC relative to kanamycin against kanamycin-sensitive strains and 128 to >256-fold improvement in the MIC relative to kanamycin against kanamycinresistant strains. Interestingly, P14KanS demonstrated potent activity against several multidrugresistant clinical isolates including methicillin-resistant S. aureus (MRSA USA400), methicillinresistant S. epidermidis (MRSE) and vancomycin-resistant E. faecium (VRE) (Table 1). Of particular note, P14KanS demonstrated potent activity against A. baumannii ATCC BAA-1605, a multidrug-resistant isolate obtained from the sputum of a Canadian soldier serving in Afghanistan. This strain is resistant to numerous antibiotics including kanamycin, meropenem, imipenem, ceftazidime, ciprofloxacin, piperacillin, ticarcillin, cefepime, aztreonam and gentamicin (Table 1). Moreover, P14KanS demonstrated potent activity against colistin-resistant P. aeruginosa (1109) isolated from a cystic fibrosis patient [28]. This isolate exhibits high-level resistance to colistin $(\mathrm{MIC}=128 \mu \mathrm{M})$, kanamycin and several antimicrobial peptides [28]. Colistin is an antibiotic of last resort for multidrug-resistant $P$. aeruginosa infections [29]. The emergence of resistant isolates to colistin, particularly via plasmid-mediated resistance in Enterobacteriaceae [30], highlights the urgent need to discover new antimicrobial agents to address this issue. The discovery that P14KanS has potent activity against a colistin-resistant $P$. aeruginosa strain indicates a potential therapeutic advantage of P14KanS over several antimicrobials that are ineffective against colistin-resistant $P$. aeruginosa [28].

\subsection{Mechanism of action of P14KanS}

In order to gain insight into the mode of action of P14KanS and its activity against kanamycin-resistant strains, we performed a series of experiments to explore its antibacterial mode of action against these isolates. First, damage to the bacterial outer membrane by P14KanS was monitored by measuring the fluorescent intensity of $P$. aeruginosa PAO1 mixed with 1-N- 
phenylnaphthylamine (NPN) and incubated with varying concentrations of the conjugate. As demonstrated in Fig. 2a, similar to the known membrane targeting antibiotic colistin, there was a significant and dose-dependent increase of fluorescence intensity of $P$. aeruginosa cultures treated with P14KanS. This was not observed with either kanamycin or the P14LRR peptide alone. Remarkably, P14KanS demonstrated more potent activity than colistin. These findings indicate that P14KanS likely targets the bacterial outer membrane leading to partitioning of NPN into the outer membrane and increased fluorescence. Damage of the bacterial inner (cytoplasmic) membrane by P14KanS was monitored by measuring the fluorescence intensity of $P$. aeruginosa PAO1 mixed with propidium iodide and treated with P14KanS. As demonstrated in Fig. 2b, the fluorescence intensity didn't change in untreated bacteria or bacteria treated with either kanamycin or P14LRR, confirming the cytoplasmic membrane remained intact. However, when P14KanS and colistin were added to bacterial cultures, a rapid and significant increase in fluorescence due to access of propidium iodide inside the bacterial cytoplasm was evident. The membrane damaging effect was both concentration- and time-dependent. For example, at $10 \times$ MIC, P14KanS demonstrated more potent membrane perturbation than at $5 \times$ MIC.

To confirm our results of membrane permeabilization against a Gram-positive pathogen, we studied the effect of P14KanS on S. epidermidis (kanamycin-resistant) membranes using a calcein leakage assay. Calcein AM is a non-fluorescent derivative that is able to penetrate cell membranes; once inside the cells it is hydrolyzed by intracytoplasmic esterases to a fluorescent calcein, which is non-permeable to membranes [19, 31]. Damage of membrane integrity is indicated by calcein leakage from bacterial cells, which is in turn proportional to a reduction in fluorescence intensity. Similar to the membrane damaging peptide, nisin (Fig. 2c), P14KanS damaged the $S$. epidermidis cell membrane that led to fast leakage of preloaded calcein within 
seconds (Fig. 2c). However, P14LRR alone demonstrated no leakage implying a non-lytic mechanism of action for the peptide. Collectively, these data confirm the membrane-disruptive effect of P14KanS against Gram-negative and Gram-positive bacteria and clarify why P14KanS demonstrated efficacy against kanamycin-resistant isolates.

\subsection{Time-kill assay against logarithmic and stationary phase bacteria}

After confirming that P14KanS possessed excellent antibacterial activity against a broadspectrum of multidrug-resistant clinical isolates, we next assessed its killing kinetics against logarithmic phase of select Gram-positive (S. aureus ATCC 6538 and S. epidermidis ATCC 35984) and Gram-negative pathogens (P. aeruginosa PAO1 and A. baumannii ATCC BAA1605). As demonstrated in Fig. 3, P14KanS rapidly killed Gram-positive bacteria. At $10 \mu \mathrm{M}$, P14KanS completely eradicated logarithmic cultures of S. aureus ATCC 6538 and S. epidermidis ATCC 35984 after 30 minutes and two hours, respectively. However, kanamycin required six hours to eradicate $S$. aureus and was not effective against $S$. epidermidis. P14LRR was not effective at the same concentration. In contrast, vancomycin demonstrated slower killing kinetics. As shown in Fig. 3, vancomycin produced a 2.5 log reduction after six hours. Linezolid exhibited a bacteriostatic effect against both species of staphylococci.

Similar to Gram-positive pathogens, P14KanS rapidly killed Gram-negative bacteria. At $20 \mu \mathrm{M}, \mathrm{P} 14 \mathrm{KanS}$ completely eradicated logarithmic cultures of $P$. aeruginosa and A. baumannii after one hour. However, kanamycin and P14LRR were not effective. Tobramycin and gentamicin eliminated $P$. aeruginosa PAO1 within two to three hours. Tobramycin eliminated $A$. baumannii ATCC BAA-1605 after three hours. Antimicrobials with fast bactericidal activity 
have several advantages including limiting spread of infection, improving treatment prognosis, limiting the emergence of resistance, and reducing duration of treatment [32].

Next, we examined the impact of P14KanS and select antibiotics against bacteria in stationary-phase. This population of cells is known to contain a high percentage of persisters that are tolerant to many antimicrobial agents and contributes to recurring infections [7, 33-35]. As shown in Fig. 3, P14KanS completely eradicated bacterial cultures of $S$. aureus after four hours and demonstrated rapid bactericidal activity (3- $\log _{10}$ reduction) against $S$. epidermidis. On the other hand, several commercial antibiotics were unable to exhibit a bactericidal effect on stationary phase bacteria, despite their bactericidal activity against logarithmic bacteria. Kanamycin demonstrated only a $1.3 \log _{10}$ reduction of $S$. aureus after six hours. Vancomycin and linezolid were not effective against stationary bacteria within the same time frame (Fig. 3).

A similar trend was observed against Gram-negative bacteria in stationary phase of growth. Treatment of stationary-phase $P$. aeruginosa and A. baumannii with $20 \mu \mathrm{M}$ of P14KanS resulted in rapid bactericidal activity (3- $\log _{10}$ reduction) and complete eradication of a high starting inoculum $\left(10^{9} \mathrm{CFU} / \mathrm{ml}\right)$ after three hours and six hours, respectively (Fig. 4). Conventional antibiotics had minimal impact on stationary-phase bacteria which is in agreement with previous findings [7, 33-35].

The superior activity of P14KanS when compared to conventional antibiotics, against stationary phase bacteria most likely is attributed to its unique antimicrobial mechanism of action. Many antibiotics require bacteria to be growing and metabolically active in order to inhibit their molecular target(s), including protein synthesis (linezolid, tobramycin and gentamicin) and cell wall synthesis (vancomycin) [36]. In contrast, as mentioned above, the positive charge present in P14KanS serves as a point of attraction with negatively-charged 
bacterial cell membranes and consequently leads to targeted disruption of the bacterial cell membrane and leakage of intracellular contents $[37,38]$. This unique mechanism of action of P14KanS would not require cells to be metabolically active and would not be impaired by the dormant and quiescent state of bacteria present in stationary phase of growth [36]. The results obtained above provide valuable insight into examining P14KanS as a potential future therapeutic option for persistent and chronic bacterial infections.

\subsection{Efficacy of P14KanS on established biofilms}

Biofilms are aggregated bacterial communities covered by a polysaccharide matrix that protects bacteria from host immune defenses and hinders antibiotics from targeting deep-seated bacteria encased within the biofilm [39]. Furthermore, biofilms act as an infectious niche with sustained release of bacteria inside the host that leads to disease relapses and therapy failure[40]. Biofilm development has been linked to serious infections including pneumonia in cystic fibrosis patients, colonization of medical devices, and urinary tract infections [41]. Biofilms pose a serious medical challenge that is difficult to control and there is a critical need to find agents that can address this problem. We examined the capability of P14KanS and control antibiotics to disrupt established biofilms of four different bacterial isolates responsible for major biofilm infections - S. aureus, S. epidermidis, P. aeruginosa and A. baumannii. As presented in Fig. 5, P14KanS disrupted mature (24 hour) biofilms more potently than several antibiotics of choice. P14KanS was superior to kanamycin and the peptide P14LRR against the kanamycin sensitive isolate (S. aureus). P14KanS demonstrated a concentration-dependent biofilm-disruptive activity. P14KanS, at a low concentration $(1 \mu \mathrm{M})$, disrupted more than $65 \%$ of the biofilm mass of $S$. aureus $(p<0.05)$ whereas kanamycin and P14LRR were not effective at the same concentrations (Fig. 5a). At higher concentrations, P14KanS disrupted more than $75 \%$ and $82 \%$ 
of biofilm mass of $S$. aureus, at 4 and $8 \mu \mathrm{M}$, respectively, $(p<0.05)$. Kanamycin, vancomycin and linezolid, at $8 \mu \mathrm{M}$, reduced approximately $50 \%$ of biofilm mass $(p<0.05)$; whereas, P14LRR was not effective (Fig. 5a).

We further assessed the efficacy of P14KanS against biofilms of a clinical multidrugresistant strain of S. epidermidis ATCC 35984, a high slime producing strain that was isolated from septicemic patients with colonized intravascular catheters in Tennessee, US[42]. This strain is resistant to several antibiotics including methicillin, erythromycin, kanamycin, gentamicin, clindamycin and trimethoprim. The great thickness of the exopolysaccharide matrix of $S$. epidermidis biofilms cause it to become extremely resilient to penetration by antibiotics [39, 4345]. Indeed, mature biofilms of $S$. epidermidis were less susceptible to vancomycin and linezolid even at $64 \mu \mathrm{M}$ (equivalent to $64-128 \times \mathrm{MIC}$ ) where only $25-30 \%$ biofilm mass reduction was observed (Fig. 5b). However, P14KanS disrupted more than 30\%, 50\%, 70\%, and $80 \%$ of biofilm mass at 8, 16, 32 and $64 \mu \mathrm{M}$, respectively, $(P<0.05)$. The peptide alone, P14LRR, was ineffective except at $64 \mu \mathrm{M}$, disrupting approximately $50 \%$ of the biofilm mass. Kanamycin did not disrupt or reduce the biofilm mass of S. epidermidis (Fig. 5b).

Remarkably, P14KanS was capable of eradicating $P$. aeruginosa and A. baumannii biofilms at $32 \mu \mathrm{M}$, however, kanamycin was not effective (Fig. 5c). P14LRR (32 $\mu \mathrm{M})$ was ineffective against $P$. aeruginosa biofilms and demonstrated only $30 \%$ reduction of $A$. baumannii biofilm mass (Fig. 5c). Collectively, the data demonstrate that P14KanS is superior to conventional antibiotics in penetrating and disrupting adherent biofilms of both Gram-positive and Gram-negative pathogens.

\subsection{Toxicity of P14KanS against mammalian cells}


A significant limitation for translating novel membrane active antimicrobials into clinical applications is their toxicity to host cells [46]. Herein, we assessed the hemolytic activity of P14KanS on human red blood cells (RBCs). As demonstrated in Fig. 6a, P14KanS and P14LRR displayed no hemolysis even at very high concentrations $(256 \mu \mathrm{M})$ (therapeutic index "TI" >256). In contrast, melittin completely lysed RBCs at very low concentrations ( $8 \mu \mathrm{M})$ equal to $1 / 2$ $\times$ MIC of melittin against $P$. aeruginosa $(\mathrm{TI}=0.5)$. The inability of P14KanS to lyse human RBCs at high concentrations confirms the selectivity of P14KanS toward the negatively-charged bacterial membranes.

Next, we evaluated the cytotoxic effects of P14KanS against human keratinocytes ( $\mathrm{HaCaT}$ cells) and HeLa cells via the MTS assay. The half maximal effective concentration $\left(\mathrm{EC}_{50}\right.$ ) was $128 / 256 \mu \mathrm{M}$, respectively, in the case of HeLa / HaCaT cells (Fig. 6b). This confirms that P14KanS displays a high safety threshold. The therapeutic index of P14KanS is 128/256 respectively, in the case of $\mathrm{HeLa} / \mathrm{HaCaT}$ cells. The data further supports the notion that P14KanS is selectively active against bacterial cells.

\subsection{Intracellular antibacterial activity of P14KanS}

For many years, S. aureus was considered to be mainly an extracellular pathogen. However, extensive studies have revealed that these pathogens can gain entry and persist inside both phagocytic and non-phagocytic eukaryotic cells, such as alveolar macrophages and keratinocytes [47-49]. The intracellular persistence of pathogens constitutes a significant challenge as they are able to avoid host immune defenses. Additionally, intracellular pathogens evade the action of many antibiotics that exhibit low intracellular penetration ability such as aminoglycosides and vancomycin[50]. Eradication of these challenging bacterial pathogens is critical to ensure successful treatment of persistent intracellular bacterial infections. Here, we investigated if 
P14KanS had the ability to kill intracellular S. aureus residing in human keratinocytes. As demonstrated in Fig. 7, P14KanS showed significant reduction of intracellular S. aureus and MRSA USA400 at nontoxic concentrations. P14KanS was the most potent agent against intracellular S. aureus, as it reduced S. aureus ATCC 6538 and MRSA USA400 by $2.52 \pm 0.37$ and $1.24 \pm 0.26 \log$, respectively at $15 \mu \mathrm{M}$. In contrast, peptide P14LRR was not effective. Kanamycin and vancomycin produced approximately 0.4-0.6 log reduction of intracellular $S$. aureus ATCC 6538 and MRSA USA400. The potent intracellular activity of P14KanS may be useful in treating certain chronic exacerbating skin diseases such as Darier's disease (keratosis follicularis) where $S$ aureus persists inside keratinocytes leading to failures in antibiotic therapy and recurrent infections in patients [51].

\subsection{Anti-inflammatory effect of P14KanS}

A key virulence factor unique to Gram-negative bacterial pathogens is the presence of lipopolysaccharide (LPS). LPS is a principal structure of the outer membrane of Gram-negative bacteria. During bacterial death, cell replication or exposure to certain antibiotics, LPS is released from bacteria leading to stimulation of proinflammatory cytokine release such as tumor necrosis factor- $\alpha$ (TNF- $\alpha$ ) and interleukin-6 (IL-6) from mononuclear phagocytes. Excessive LPS exposure leads to overproduction of these cytokines which can result in septic shock and death. Annually there are 18 million cases of septic shock globally with a mortality rate of $\sim 30 \%$ $[52,53]$. Therefore, identifying agents that are capable of neutralizing LPS is critical.

We investigated if P14KanS could bind to and neutralize the effect of LPS. As presented in Fig. 8a, P14KanS and the peptide P14LRR were able to bind to LPS in vitro as evident by inhibition of the LPS-induced activation of the LAL enzyme (Limulus amoebocyte lysate). P14KanS, P14LRR and colistin (a known LPS-binding agent) produced 60.8\% $\pm 6.5,71.2 \% \pm 5$ 
and $79.76 \% \pm 4.6$ inhibition of the LAL enzyme at $10 \mu \mathrm{M}$, respectively. However, kanamycin demonstrated only minimal inhibition $(6.9 \% \pm 3.5)$ at the same concentration.

Next, we examined if P14KanS and the peptide, P14LRR could reduce the endotoxininduced proinflammatory cytokine response in murine macrophages by measuring cytokine levels using ELISA. As depicted in Fig. 8b, P14KanS and P14LRR were able to inhibit LPSinduced proinflammatory cytokines in macrophages in a manner similar to colistin. P14KanS, P14LRR and colistin, at $10 \mu \mathrm{M}$, decreased TNF- $\alpha$ levels by $65.53 \% \pm 2.45,68.4 \% \pm 5.43$, $97.53 \% \pm 0.32$, respectively; and IL-6 levels by $74.71 \% \pm 9.10,81.92 \% \pm 0.78$ and $95.04 \% \pm$ $0.56 \%$, respectively. Kanamycin, in contrast, produced an $11.41 \% \pm 4.5$ and $10 \% \pm 3.30$ inhibition of TNF- $\alpha$ and IL-6 levels, respectively. The capability of P14KanS to reduce endotoxin-mediated proinflammatory cytokine production provides a potential avenue for its development as an antibacterial agent to treat sepsis and also as an adjunctive with antibiotics to overcome sepsis.

\subsection{Multi-step resistance selection}

To examine if the selective membrane damaging of P14KanS can overcome traditional mechanisms of antibiotic resistance, we serially passaged a kanamycin-sensitive $S$. aureus isolate (ATCC 6538) with sub-inhibitory concentrations of P14KanS, kanamycin, P14LRR and three different classes of antibiotics, ampicillin (cell wall synthesis inhibitor), rifampicin (RNA synthesis inhibitor) and ciprofloxacin (DNA synthesis inhibitor) for eight days. The MIC was determined daily using the broth microdilution assay. As presented in Fig. 9, S. aureus did not develop resistance to P14KanS for six passages and only a four-fold change in MIC was observed after eight passages. However, treatment of S. aureus with kanamycin induced a rapid shift in the MIC within the fourth passage and resulted in a 64-fold increase in kanamycin's MIC 
by the seventh passage. The MIC of P14LRR increased by four and 16-fold by the sixth and eighth passages, respectively. The MIC of rifampicin and ampicillin increased to 64-fold and ciprofloxacin increased 16-fold by the sixth passage (Fig. 9). Thus, the conjugation of kanamycin with P14LRR appears to decrease the emergence of resistance to either agent alone. Given P14KanS acts by disrupting bacterial cell membranes, bacteria would need to undergo significant changes to their membrane lipid composition in order for resistance to occur [54]. These alterations are extremely difficult for bacteria to produce compared to point mutations in specific genes [36, 55]. This result suggests that the selective membrane-disrupting activity of P14KanS may be able to effectively overcome conventional mechanisms of antibiotic resistance.

\subsection{In vivo efficacy of P14KanS in a C. elegans infection model.}

In order to validate the antibacterial efficacy of the peptide kanamycin conjugate in vivo, we utilized a $C$. elegans model of bacterial infection. This model has been used extensively utilized for early-stage evaluation of promising antimicrobials [56-58]. Moreover, this model demonstrated that bacteria can develop a biofilm infection inside the gut of C. elegans [59-61].

Bolstered by our in vitro results, we examined whether P14KanS could protect infected worms from the cidal activity of bacteria. Interestingly, P14KanS significantly increased the rate of survival for $C$. elegans infected with either $P$. aeruginosa or A. baumannii, giving complete protection for 72 hours (Fig. 10). However, kanamycin alone and P14LRR administered alone failed to protect the worms. P. aeruginosa PAO1 and A. baumannii completely killed untreated worms after 36 and 72 hours, respectively (Fig. 10).

The survival experiment with $C$. elegans was next utilized to examine the impact of biofilmforming S. aureus. While kanamycin and P14LRR failed to protect worms from being killed by a kanamycin-sensitive isolate (S. aureus ATCC 6538), P14KanS at $10 \mu \mathrm{M}$, significantly increased 
the survival rate of $C$. elegans, giving nearly complete protection for 72 hours (Fig. 10). Next, we evaluated P14KanS's ability to rescue $C$. elegans from infection by the multidrug-resistant clinical isolate, S. epidermidis ATCC 35984 (NRS 101). Indeed, this strain demonstrated higher virulence than $S$. aureus as it completely killed untreated $C$. elegans after 72 hours. A notable protective effect was provided by P14KanS, but not with kanamycin or P14LRR. P14KanS rescued $80 \%$ of infected worms after 72 hours. Interestingly, P14KanS was superior to drugs of choice (vancomycin and linezolid) as they protected approximately $70 \%$ and $60 \%$ of S. aureus and S. epidermidis infected worms, respectively at the same test concentrations $(10 \mu \mathrm{M})$ (Fig. 10). Collectively, these data validate the efficacy of P14KanS in vivo against infections caused by biofilm-forming strains of Gram-positive and Gram-negative bacteria.

\section{Conclusion}

The worldwide increase of antibiotic resistance and limited supply of new antibiotics necessitates the discovery and development of novel approaches to address this burgeoning challenge. In the present study, we conjugated the aminoglycoside antibiotic, kanamycin with the antibacterial peptide P14LRR to enhance the antibiotic's potency and spectrum of activity against resistant bacterial strains. This conjugation successfully improved the antibacterial activity of kanamycin against both kanamycin-sensitive and kanamycin-resistant strains of key ESKAPE pathogens. P14KanS was found to exert its antibacterial activity via disruption of both the outer and inner membranes of the cell envelope. However, no adverse toxic effect was observed to mammalian cells at concentrations 128 times higher than the MIC, indicating P14KanS possesses a selective membrane-active effect to bacterial cells. The rapid, membrane-disruptive nature of P14KanS against bacteria shows low propensity for resistance development in comparison to kanamycin and conventional antibiotics. In addition to its potent antibacterial activity, P14KanS 
significantly disrupted established bacterial biofilms more so than conventional antibiotics. Furthermore, P14KanS was capable of binding strongly to LPS and subsequently reduced the endotoxin-mediated proinflammatory cytokine production in murine macrophage cells. This discovery highlights a potential avenue for development of P14KanS to treat sepsis. P14KanS also significantly reduced the burden of intracellular MRSA potentially opening an avenue for exploring P14KanS for treatment of certain chronic skin diseases, such as Darier's disease. Furthermore, P14KanS's potent antibacterial activity was confirmed in vivo as it significantly increased the rate of survival for nematodes infected with both Gram-positive and Gram-negative pathogens. The conjugation of kanamycin with a cell-penetrating peptide has great potential to facilitate delivery of drugs directly to the site of infection (lungs) via intrapulmonary delivery [62]. Clearly, further investigation of potential clinical applications is necessary in more advanced animal models of infection. The success of this approach will open the door for further testing of other aminoglycosides and different classes of antibiotics conjugated to antimicrobial peptides.

\section{Author contributions}

M.M. performed the experiments. A.B. synthesized the compounds. M.M., J.C and M.S. designed the study, analyzed the data and interpreted the results. M.M., H.M., J.C and M.S. wrote the manuscript. All authors reviewed and discussed the results.

\section{Funding}

The National Science Foundation (1012316-CHE) is acknowledged for financial support.

\section{Conflicts of interest}

None to declare. 


\section{Acknowledgments}

We are very grateful to Dr. Samuel M. Moskowitz, Harvard Medical School, for sharing the colistin-resistant $P$. aeruginosa isolate. The authors would like to thank BEI resources, NIAID, NIH for providing bacterial strains used in this study. Mohamed F. Mohamed is supported by a scholarship from the Egyptian Cultural and Educational Bureau (ECEB) in Washington DC, USA.

\section{References}

[1] L.R. Peterson, Bad bugs, no drugs: no ESCAPE revisited, Clinical infectious diseases : an official publication of the Infectious Diseases Society of America, 49 (2009) 992-993.

[2] CDC, Antibiotic resistance threats in the United States, http://www.cdc.gov/drugresistance/threat-report-2013/pdf/ar-threats-2013-508.pdf, (2013).

[3] H.W. Boucher, G.H. Talbot, J.S. Bradley, J.E. Edwards, D. Gilbert, L.B. Rice, M. Scheld, B. Spellberg, J. Bartlett, Bad bugs, no drugs: no ESKAPE! An update from the Infectious Diseases Society of America, Clinical infectious diseases : an official publication of the Infectious Diseases Society of America, 48 (2009) 1-12.

[4] A.P. Magiorakos, A. Srinivasan, R.B. Carey, Y. Carmeli, M.E. Falagas, C.G. Giske, S. Harbarth, J.F. Hindler, G. Kahlmeter, B. Olsson-Liljequist, D.L. Paterson, L.B. Rice, J. Stelling, M.J. Struelens, A. Vatopoulos, J.T. Weber, D.L. Monnet, Multidrug-resistant, extensively drugresistant and pandrug-resistant bacteria: an international expert proposal for interim standard definitions for acquired resistance, Clinical Microbiology and Infection, 18 (2012) 268-281.

[5] A. Correa, R. del Campo, M. Perenguez, V.M. Blanco, M. Rodríguez-Baños, F. Perez, J.J. Maya, L. Rojas, R. Cantón, C.A. Arias, M.V. Villegas, Dissemination of High-Risk Clones of Extensively Drug-Resistant Pseudomonas aeruginosa in Colombia, Antimicrobial agents and chemotherapy, 59 (2015) 2421-2425.

[6] C.Y. Wang, J.S. Jerng, K.Y. Chen, L.N. Lee, C.J. Yu, P.R. Hsueh, P.C. Yang, Pandrugresistant Pseudomonas aeruginosa among hospitalised patients: clinical features, risk-factors and outcomes, Clinical microbiology and infection : the official publication of the European Society of Clinical Microbiology and Infectious Diseases, 12 (2006) 63-68.

[7] L.R. Mulcahy, J.L. Burns, S. Lory, K. Lewis, Emergence of Pseudomonas aeruginosa strains producing high levels of persister cells in patients with cystic fibrosis, Journal of bacteriology, 192 (2010) 6191-6199.

[8] N. Hoiby, O. Ciofu, T. Bjarnsholt, Pseudomonas aeruginosa biofilms in cystic fibrosis, Future Microbiol, 5 (2010) 1663-1674. 
[9] S. Shakil, R. Khan, R. Zarrilli, A.U. Khan, Aminoglycosides versus bacteria--a description of the action, resistance mechanism, and nosocomial battleground, J Biomed Sci, 15 (2008) 5-14.

[10] M.P. Mingeot-Leclercq, Y. Glupczynski, P.M. Tulkens, Aminoglycosides: activity and resistance, Antimicrobial agents and chemotherapy, 43 (1999) 727-737.

[11] S.B. Vakulenko, S. Mobashery, Versatility of Aminoglycosides and prospects for their future, Clinical microbiology reviews, 16 (2003) 430-+.

[12] K. Poole, Aminoglycoside resistance in Pseudomonas aeruginosa, Antimicrobial agents and chemotherapy, 49 (2005) 479-487.

[13] J. Kuriakose, V. Hernandez-Gordillo, M. Nepal, A. Brezden, V. Pozzi, M.N. Seleem, J. Chmielewski, Targeting intracellular pathogenic bacteria with unnatural proline-rich peptides: coupling antibacterial activity with macrophage penetration, Angew Chem Int Ed Engl, 52 (2013) 9664-9667.

[14] A. Brezden, M.F. Mohamed, M. Nepal, J.S. Harwood, J. Kuriakose, M.N. Seleem, J. Chmielewski, Dual Targeting of Intracellular Pathogenic Bacteria with a Cleavable Conjugate of Kanamycin and an Antibacterial Cell-Penetrating Peptide, J Am Chem Soc, (2016).

[15] CLSI, Methods for dilution antimicrobial susceptibility tests for bacteria that grow aerobically; approved standard M7-A7. CLSI, Wayne, PA, (2007).

[16] J. Yan, K. Wang, W. Dang, R. Chen, J. Xie, B. Zhang, J. Song, R. Wang, Two hits are better than one: membrane-active and DNA binding-related double-action mechanism of NK-18, a novel antimicrobial peptide derived from mammalian NK-lysin, Antimicrobial agents and chemotherapy, 57 (2013) 220-228.

[17] C. Nagant, B. Pitts, K. Nazmi, M. Vandenbranden, J.G. Bolscher, P.S. Stewart, J.P. Dehaye, Identification of peptides derived from the human antimicrobial peptide LL-37 active against biofilms formed by Pseudomonas aeruginosa using a library of truncated fragments, Antimicrobial agents and chemotherapy, 56 (2012) 5698-5708.

[18] M.F. Mohamed, M.I. Hamed, A. Panitch, M.N. Seleem, Targeting Methicillin-Resistant Staphylococcus aureus with Short Salt-Resistant Synthetic Peptides, Antimicrobial agents and chemotherapy, 58 (2014) 4113-4122.

[19] Y.Q. Xiong, K. Mukhopadhyay, M.R. Yeaman, J. Adler-Moore, A.S. Bayer, Functional interrelationships between cell membrane and cell wall in antimicrobial peptide-mediated killing of Staphylococcus aureus, Antimicrobial agents and chemotherapy, 49 (2005) 3114-3121.

[20] M.F. Mohamed, G.K. Hammac, L. Guptill, M.N. Seleem, Antibacterial activity of novel cationic peptides against clinical isolates of multi-drug resistant Staphylococcus pseudintermedius from infected dogs, PloS one, 9 (2014) e116259.

[21] G.A. O'Toole, Microtiter dish biofilm formation assay, J Vis Exp, (2011).

[22] M.F. Mohamed, A. Abdelkhalek, M.N. Seleem, Evaluation of short synthetic antimicrobial peptides for treatment of drug-resistant and intracellular Staphylococcus aureus, Scientific reports, 6 (2016) 29707.

[23] - Introduction of a Lysine Residue Promotes Aggregation of Temporin L in Lipopolysaccharides and Augmentation of Its Antiendotoxin Property.pdf>.

[24] M.F. Mohamed, M.N. Seleem, Efficacy of short novel antimicrobial and anti-inflammatory peptides in a mouse model of methicillin-resistant Staphylococcus aureus (MRSA) skin infection, Drug design, development and therapy, 8 (2014) 1979-1983.

[25] S. Thangamani, W. Younis, M.N. Seleem, Repurposing ebselen for treatment of multidrugresistant staphylococcal infections, Scientific reports, 5 (2015) 11596. 
[26] T.I. Moy, A.R. Ball, Z. Anklesaria, G. Casadei, K. Lewis, F.M. Ausubel, Identification of novel antimicrobials using a live-animal infection model, Proceedings of the National Academy of Sciences of the United States of America, 103 (2006) 10414-10419.

[27] E. Tampakakis, I. Okoli, E. Mylonakis, A C. elegans-based, whole animal, in vivo screen for the identification of antifungal compounds, Nature protocols, 3 (2008) 1925-1931.

[28] S.M. Moskowitz, M.K. Brannon, N. Dasgupta, M. Pier, N. Sgambati, A.K. Miller, S.E. Selgrade, S.I. Miller, M. Denton, S.P. Conway, H.K. Johansen, N. Hoiby, PmrB mutations promote polymyxin resistance of Pseudomonas aeruginosa isolated from colistin-treated cystic fibrosis patients, Antimicrobial agents and chemotherapy, 56 (2012) 1019-1030.

[29] M.E. Falagas, S.K. Kasiakou, Colistin: the revival of polymyxins for the management of multidrug-resistant gram-negative bacterial infections, Clinical infectious diseases : an official publication of the Infectious Diseases Society of America, 40 (2005) 1333-1341.

[30] Y.-Y. Liu, Y. Wang, T.R. Walsh, L.-X. Yi, R. Zhang, J. Spencer, Y. Doi, G. Tian, B. Dong, X. Huang, L.-F. Yu, D. Gu, H. Ren, X. Chen, L. Lv, D. He, H. Zhou, Z. Liang, J.-H. Liu, J. Shen, Emergence of plasmid-mediated colistin resistance mechanism MCR-1 in animals and human beings in China: a microbiological and molecular biological study, The Lancet Infectious Diseases, (2015).

[31] S.P. Koo, A.S. Bayer, M.R. Yeaman, Diversity in antistaphylococcal mechanisms among membrane-targeting antimicrobial peptides, Infection and immunity, 69 (2001) 4916-4922.

[32] J. Alder, B. Eisenstein, The Advantage of Bactericidal Drugs in the Treatment of Infection, Curr Infect Dis Rep, 6 (2004) 251-253.

[33] B.P. Conlon, E.S. Nakayasu, L.E. Fleck, M.D. LaFleur, V.M. Isabella, K. Coleman, S.N. Leonard, R.D. Smith, J.N. Adkins, K. Lewis, Activated ClpP kills persisters and eradicates a chronic biofilm infection, Nature, 503 (2013) 365-370.

[34] S. Lechner, K. Lewis, R. Bertram, Staphylococcus aureus persisters tolerant to bactericidal antibiotics, J Mol Microbiol Biotechnol, 22 (2012) 235-244.

[35] I. Keren, N. Kaldalu, A. Spoering, Y. Wang, K. Lewis, Persister cells and tolerance to antimicrobials, FEMS microbiology letters, 230 (2004) 13-18.

[36] J.G. Hurdle, A.J. O'Neill, I. Chopra, R.E. Lee, Targeting bacterial membrane function: an underexploited mechanism for treating persistent infections, Nature reviews. Microbiology, 9 (2011) 62-75.

[37] B. Deslouches, J.D. Steckbeck, J.K. Craigo, Y. Doi, T.A. Mietzner, R.C. Montelaro, Rational design of engineered cationic antimicrobial peptides consisting exclusively of arginine and tryptophan, and their activity against multidrug-resistant pathogens, Antimicrobial agents and chemotherapy, 57 (2013) 2511-2521.

[38] Z.Y. Ong, J. Cheng, Y. Huang, K. Xu, Z. Ji, W. Fan, Y.Y. Yang, Effect of stereochemistry, chain length and sequence pattern on antimicrobial properties of short synthetic beta-sheet forming peptide amphiphiles, Biomaterials, 35 (2014) 1315-1325.

[39] J.W. Costerton, Z. Lewandowski, D.E. Caldwell, D.R. Korber, H.M. Lappin-Scott, Microbial biofilms, Annu Rev Microbiol, 49 (1995) 711-745.

[40] T.F. Mah, G.A. O'Toole, Mechanisms of biofilm resistance to antimicrobial agents, Trends in microbiology, 9 (2001) 34-39.

[41] N. Hoiby, T. Bjarnsholt, M. Givskov, S. Molin, O. Ciofu, Antibiotic resistance of bacterial biofilms, International journal of antimicrobial agents, 35 (2010) 322-332. 
[42] G.D. Christensen, A.L. Bisno, J.T. Parisi, B. McLaughlin, M.G. Hester, R.W. Luther, Nosocomial septicemia due to multiply antibiotic-resistant Staphylococcus epidermidis, Ann Intern Med, 96 (1982) 1-10.

[43] J.B. Kaplan, C. Ragunath, K. Velliyagounder, D.H. Fine, N. Ramasubbu, Enzymatic detachment of Staphylococcus epidermidis biofilms, Antimicrobial agents and chemotherapy, 48 (2004) 2633-2636.

[44] R. Singh, P. Ray, A. Das, M. Sharma, Penetration of antibiotics through Staphylococcus aureus and Staphylococcus epidermidis biofilms, The Journal of antimicrobial chemotherapy, 65 (2010) 1955-1958.

[45] D.L. Williams, R.D. Bloebaum, Observing the biofilm matrix of Staphylococcus epidermidis ATCC 35984 grown using the CDC biofilm reactor, Microsc Microanal, 16 (2010) 143-152.

[46] M. Zasloff, Antimicrobial peptides of multicellular organisms, Nature, 415 (2002) 389-395.

[47] G. Soong, F. Paulino, S. Wachtel, D. Parker, M. Wickersham, D. Zhang, A. Brown, C. Lauren, M. Dowd, E. West, B. Horst, P. Planet, A. Prince, Methicillin-resistant Staphylococcus aureus adaptation to human keratinocytes, mBio, 6 (2015).

[48] C. von Eiff, K. Becker, D. Metze, G. Lubritz, J. Hockmann, T. Schwarz, G. Peters, Intracellular persistence of Staphylococcus aureus small-colony variants within keratinocytes: a cause for antibiotic treatment failure in a patient with darier's disease, Clinical infectious diseases : an official publication of the Infectious Diseases Society of America, 32 (2001) 1643-1647.

[49] E. Brouillette, G. Grondin, L. Shkreta, P. Lacasse, B.G. Talbot, In vivo and in vitro demonstration that Staphylococcus aureus is an intracellular pathogen in the presence or absence of fibronectin-binding proteins, Microbial pathogenesis, 35 (2003) 159-168.

[50] J.M. Buyck, P.M. Tulkens, F. Van Bambeke, Pharmacodynamic evaluation of the intracellular activity of antibiotics towards Pseudomonas aeruginosa PAO1 in a model of THP-1 human monocytes, Antimicrobial agents and chemotherapy, 57 (2013) 2310-2318.

[51] M. Mempel, C. Schnopp, M. Hojka, H. Fesq, S. Weidinger, M. Schaller, H.C. Korting, J. Ring, D. Abeck, Invasion of human keratinocytes by Staphylococcus aureus and intracellular bacterial persistence represent haemolysin-independent virulence mechanisms that are followed by features of necrotic and apoptotic keratinocyte cell death, Br J Dermatol, 146 (2002) 943-951. [52] N.H. Lyle, O.M. Pena, J.H. Boyd, R.E. Hancock, Barriers to the effective treatment of sepsis: antimicrobial agents, sepsis definitions, and host-directed therapies, Ann N Y Acad Sci, 1323 (2014) 101-114.

[53] J. Cohen, The immunopathogenesis of sepsis, Nature, 420 (2002) 885-891.

[54] M.R. Yeaman, N.Y. Yount, Mechanisms of antimicrobial peptide action and resistance, Pharmacol Rev, 55 (2003) 27-55.

[55] R.E. Hancock, H.G. Sahl, Antimicrobial and host-defense peptides as new anti-infective therapeutic strategies, Nature biotechnology, 24 (2006) 1551-1557.

[56] D. Uccelletti, E. Zanni, L. Marcellini, C. Palleschi, D. Barra, M.L. Mangoni, AntiPseudomonas activity of frog skin antimicrobial peptides in a Caenorhabditis elegans infection model: a plausible mode of action in vitro and in vivo, Antimicrobial agents and chemotherapy, 54 (2010) 3853-3860.

[57] E. Jayamani, R. Rajamuthiah, J. Larkins-Ford, B.B. Fuchs, A.L. Conery, A. Vilcinskas, F.M. Ausubel, E. Mylonakis, Insect-derived cecropins display activity against Acinetobacter baumannii in a whole-animal high-throughput Caenorhabditis elegans model, Antimicrobial agents and chemotherapy, 59 (2015) 1728-1737. 
[58] C. de la Fuente-Nunez, F. Reffuveille, S.C. Mansour, S.L. Reckseidler-Zenteno, D. Hernandez, G. Brackman, T. Coenye, R.E. Hancock, D-enantiomeric peptides that eradicate wild-type and multidrug-resistant biofilms and protect against lethal Pseudomonas aeruginosa infections, Chem Biol, 22 (2015) 196-205.

[59] J. Begun, J.M. Gaiani, H. Rohde, D. Mack, S.B. Calderwood, F.M. Ausubel, C.D. Sifri, Staphylococcal biofilm exopolysaccharide protects against Caenorhabditis elegans immune defenses, PLoS pathogens, 3 (2007) e57.

[60] J. Begun, C.D. Sifri, S. Goldman, S.B. Calderwood, F.M. Ausubel, Staphylococcus aureus virulence factors identified by using a high-throughput Caenorhabditis elegans-killing model, Infection and immunity, 73 (2005) 872-877.

[61] S. Edwards, B.V. Kjellerup, Exploring the applications of invertebrate host-pathogen models for in vivo biofilm infections, FEMS Immunol Med Microbiol, 65 (2012) 205-214.

[62] L.N. Patel, J. Wang, K.J. Kim, Z. Borok, E.D. Crandall, W.C. Shen, Conjugation with cationic cell-penetrating peptide increases pulmonary absorption of insulin, Molecular pharmaceutics, 6 (2009) 492-503. 
Table 1: Minimum inhibitory concentration (MIC) $(\mu \mathrm{M})$ of compounds against clinical and drug-resistant bacterial isolates.

\begin{tabular}{|c|c|c|c|c|c|c|c|c|}
\hline Compound & $\begin{array}{l}\text { Methicillin- } \\
\text { resistant } S \text {. } \\
\text { aureus } \\
\text { USA400 }\end{array}$ & $\begin{array}{c}\text { S. aureus } \\
\text { ATCC } 6538\end{array}$ & $\begin{array}{l}\text { S. epidermidis } \\
\text { ATCC } 35984\end{array}$ & $\begin{array}{c}\text { P. aeruginosa } \\
\text { PAO1 }\end{array}$ & $\begin{array}{c}\text { Colistin-resistant } P \text {. } \\
\text { aeruginosa } 1109\end{array}$ & $\begin{array}{c}\text { A. baumannii } \\
\text { BAA-1605 }\end{array}$ & $\begin{array}{c}\text { K. } \\
\text { pneumoniae } \\
\text { BAA-1706 }\end{array}$ & $\begin{array}{l}\text { Vancomycin- } \\
\text { resistant } \\
\text { E. faecium } \\
\text { ATCC } 700221\end{array}$ \\
\hline Phenotype & $\begin{array}{l}\text { Resistant to } \\
\text { methicillin and } \\
\text { tetracycline }\end{array}$ & $\begin{array}{l}\text { Biofilm } \\
\text { forming } \\
\text { strain, } \\
\text { methicillin } \\
\text { sensitive }\end{array}$ & $\begin{array}{l}\text { Prototype biofilm } \\
\text { producer, resistant to } \\
\text { methicillin, } \\
\text { gentamicin, } \\
\text { kanamycin, } \\
\text { erythromycin, } \\
\text { clindamycin and } \\
\text { trimethoprim }\end{array}$ & $\begin{array}{l}\text { Biofilm } \\
\text { producing } \\
\text { strain. } \\
\text { Resistant to } \\
\text { kanamycin }\end{array}$ & $\begin{array}{l}\text { Isolated from a } \\
\text { cystic fibrosis } \\
\text { patient. } \\
\text { Resistant to colistin } \\
\text { and kanamycin }\end{array}$ & $\begin{array}{l}\text { A multidrug- } \\
\text { resistant strain; } \\
\text { resistant to } \\
\text { kanamycin, } \\
\text { ceftazidime, } \\
\text { gentamicin, } \\
\text { ticarcillin, } \\
\text { piperacillin, } \\
\text { aztreonam, } \\
\text { cefepime, } \\
\text { ciprofloxacin, } \\
\text { imipenem, and } \\
\text { meropemem }\end{array}$ & $\begin{array}{l}\text { Resistant to } \\
\text { kanamycin }\end{array}$ & $\begin{array}{l}\text { Resistant to } \\
\text { vancomycin, } \\
\text { teicoplanin and } \\
\text { kanamycin }\end{array}$ \\
\hline P14LRR & 64 & 16 & 32 & 64 & 64 & 32 & 32 & 8 \\
\hline Kanamycin & 4 & 2 & $>256$ & $>256$ & $>256$ & 128 & 256 & $>256$ \\
\hline P14KanS & 1 & 1 & 1 & 2 & 2 & 1 & 2 & 2 \\
\hline $\begin{array}{c}\text { Fold } \\
\text { enhancement in } \\
\text { MIC compared to } \\
\text { kanamycin }\end{array}$ & 4 & 2 & $>256$ & $>128$ & $>128$ & 128 & 128 & $>128$ \\
\hline
\end{tabular}




\section{Figure legends}

Figure 1: The designed dual agent (P14KanS) is composed of the antibiotic kanamycin (pink) and the antimicrobial peptide P14LRR (blue).

Figure 2: A) Permeabilization of the outer membrane of $P$. aeruginosa PAO1 by compounds as indicated by the enhanced uptake of 1-Nphenylnaphthylamine (NPN). Fluorescence intensity caused by the partitioning of NPN into the outer membrane was monitored after addition of compounds. Data are presented as means \pm standard error of the means $(n=3)$. B) Permeabilization of the inner (cytoplasmic) membrane by compounds is indicated by propidium iodide fluorescence. C) Permeabilization of the cytoplasmic membrane of kanamycin-resistant $S$. epidermidis ATCC 35984 as a function of compound concentration, indicated by percent of calcein leakage for 60 minute exposure. Each experiment was performed in triplicate, and the values represent means \pm standard deviation.

Figure 3: The killing kinetics of $\mathrm{P} 14 \mathrm{KanS}$ and control antibiotics against logarithmic (A\&B) and stationary phase (C\&D) cultures of $S$. aureus ATCC 6538 (A\&C) and S. epidermidis ATCC 35984 (B\&D). (A\&B) Logarithmic phase of bacteria were exposed to compounds at $10 \mu \mathrm{M}$. (C\&D) The killing kinetics of stationary phase of bacteria exposed to compounds at $10 \mu \mathrm{M}$. Untreated samples served as a control. The results are given as means \pm SD $(n=3)$; data without error bars indicate that the SD is too small to be seen.

Figure 4: The killing kinetics of P14KanS and control antibiotics against logarithmic (A\&B) and stationary phase (C\&D) cultures of $P$. aeruginosa PAO1 (A\&C) and A. baumannii ATCC BAA1605 (B\&D). (A\&B) Logarithmic phase of bacteria were exposed to compounds at $20 \mu \mathrm{M}$. (C\&D) The killing kinectics of stationary phase of bacteria exposed to compounds at $20 \mu \mathrm{M}$. Untreated samples served as a control. The results are given as means \pm SD $(n=3)$; data without error bars indicate that the SD is too small to be seen.

Figure 5: Efficacy of P14KanS on established biofilms of A) $S$. aureus ATCC 6538; B) $S$. epidermidis ATCC 35984; C) P. aeruginosa PAO1 and A. baumannii ATCC BAA-1605. Mature (24 hour old) biofilms were treated with different concentrations of P14KanS, P14LRR, kanamycin and control antibiotics and plates were incubated at $37{ }^{\circ} \mathrm{C}$ for 24 hours. After incubation, wells were washed and biofilms were stained with $0.5 \%$ (w/v) crystal violet for 30 minutes. The dye was solubilized with ethanol (95\%) and the optical density (OD) of biofilms was measured. Experiments were repeated twice independently and the average values are reported. Statistical analysis was calculated using one-way ANOVA, with post hoc Tukey's multiple comparisons test. $P$ values of $<0.05$ were considered significant. One asterisk $(*)$ indicates significance from the negative control. Two asterisks $(* *)$ indicate significance of P14KanS compared to P14LRR and kanamycin. Results are expressed as means from three biological replicates \pm standard deviation.

Figure 6: Toxicity of P14KanS against mammalian cells. (A) The release of hemoglobin in the supernatant of human erythrocytes after treatment with increasing amounts of P14KanS, P14LRR, and melittin was measured at $415 \mathrm{~nm}$. Triton X-100 served as a positive control. (B) Cytotoxicity assay showing the percent mean absorbance at $490 \mathrm{~nm}$ after incubating human keratinocytes (HaCaT) or HeLa cells with compounds at different concentrations. Sterile water 
(compound diluent) served as the negative control. Cell viability was measured using the MTS assay. Results are expressed as means from three measurements \pm standard deviation.

Figure 7: Intracellular antibacterial activity of P14KanS in human keratinocytes (HaCaT) infected with S. aureus. The effect of kanamycin, P14LRR, P14KanS and vancomycin, at 15 $\mu \mathrm{M}$, to kill intracellular S. aureus ATCC 6538 and MRSA USA400 inside infected HaCaT cells after treatment for 24 hours. Statistical analysis was calculated using one-way ANOVA, with post hoc Tukey's multiple comparisons test. $P$ values of $<0.05$ were considered significant. One asterisk $(*)$ indicates significance from the negative control. Two asterisks (**) indicate significance of P14KanS compared to P14LRR and kanamycin. Results are expressed as means from three biological replicates \pm standard deviation.

Figure 8: A) LPS binding activity of compounds. Compounds at $10 \mu \mathrm{M}$ were incubated with one endotoxin unit (EU) of LPS at $37^{\circ} \mathrm{C}$ for 30 minutes. Colistin was used as positive control due to its high binding affinity for LPS. The binding of compounds with LPS is expressed as percent change relative to untreated samples. B) Anti-inflammatory effect of compounds on LPS stimulated macrophage. J774A.1 cells were stimulated with LPS (150 ng/mL final concentration) in the presence of $10 \mu \mathrm{M}$ of compounds. Cells stimulated with LPS alone and untreated cells served as controls. Cells were incubated for six hours at $37^{\circ} \mathrm{C}$ after which the supernatants of the medium from each treatment were collected. Cytokine detection of tumor necrosis factor- $\alpha$ (TNF- $\alpha$ ) and interleukin-6 (IL-6) in supernatants was analyzed using ELISA. Cytokine levels are expressed as percent change relative to the LPS stimulated control.

Figure 9: Drug-resistance development profile of S. aureus ATCC 6538 over eight passages in the presence of sub-inhibitory concentrations of kanamycin, P14LRR, P14KanS and three classes of antibiotics including the cell wall synthesis inhibitor, ampicillin, the RNA synthesis inhibitor, rifampicin and the DNA synthesis inhibitor, ciprofloxacin.

Figure 10: Efficacy of P14KanS in a Caenorhabditis elegans model of bacterial infection. $C$. elegans strains glp-4; sek 1 were infected with $P$. aeruginosa PAO1, A. baumannii ATCC BAA1605, S. aureus ATCC 6538 and S. epidermidis ATCC 35984. After infection, worms were treated with P14KanS, P14LRR, kanamycin and control antibiotics. Worms were monitored daily and the live worms were counted. Results are expressed as a Kaplan-Meier survival-curve. C. elegans receiving no treatment served as a control. 


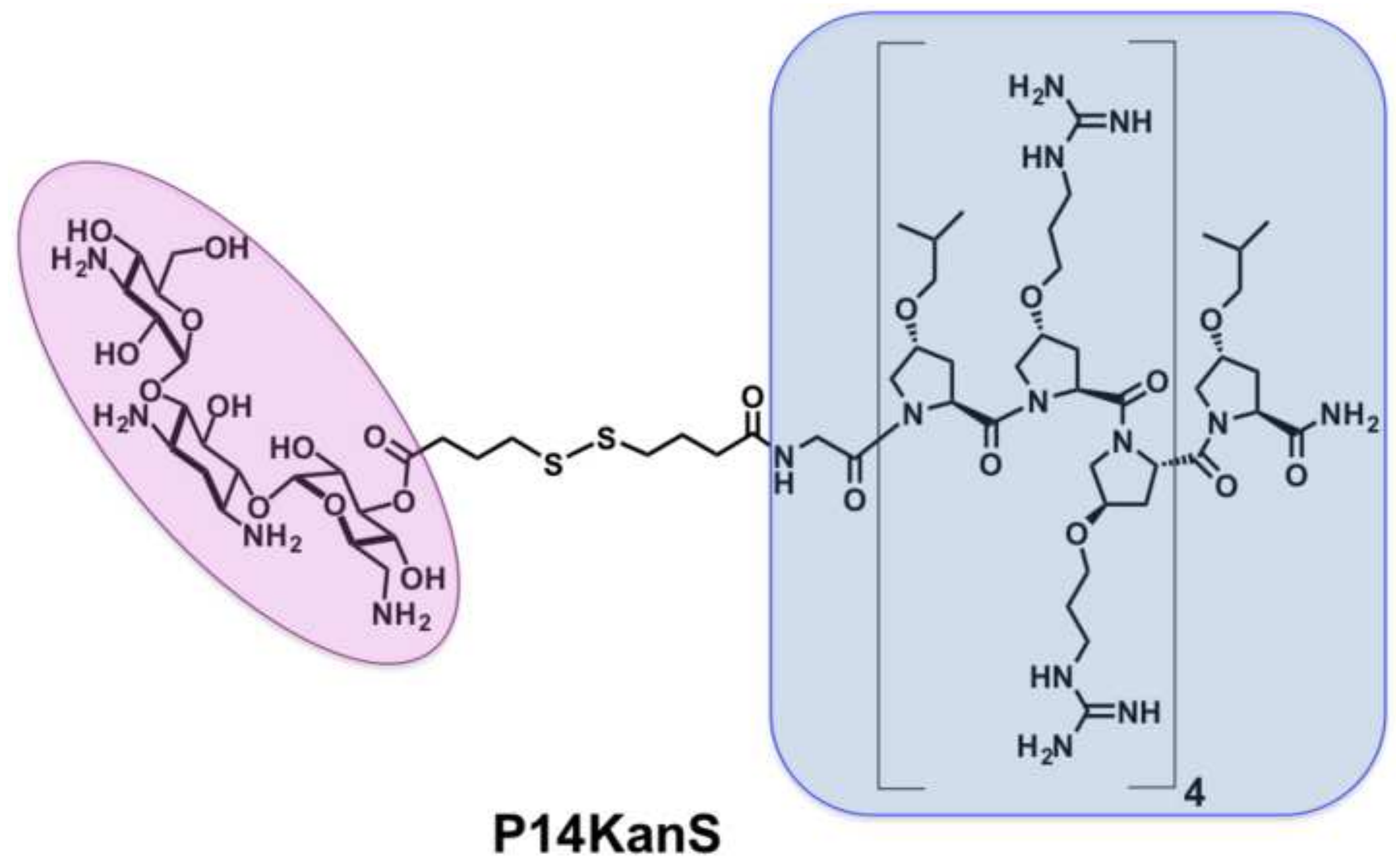


A

A

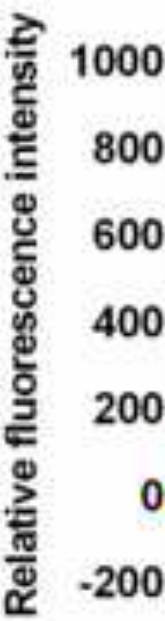

B

Time (minutes)

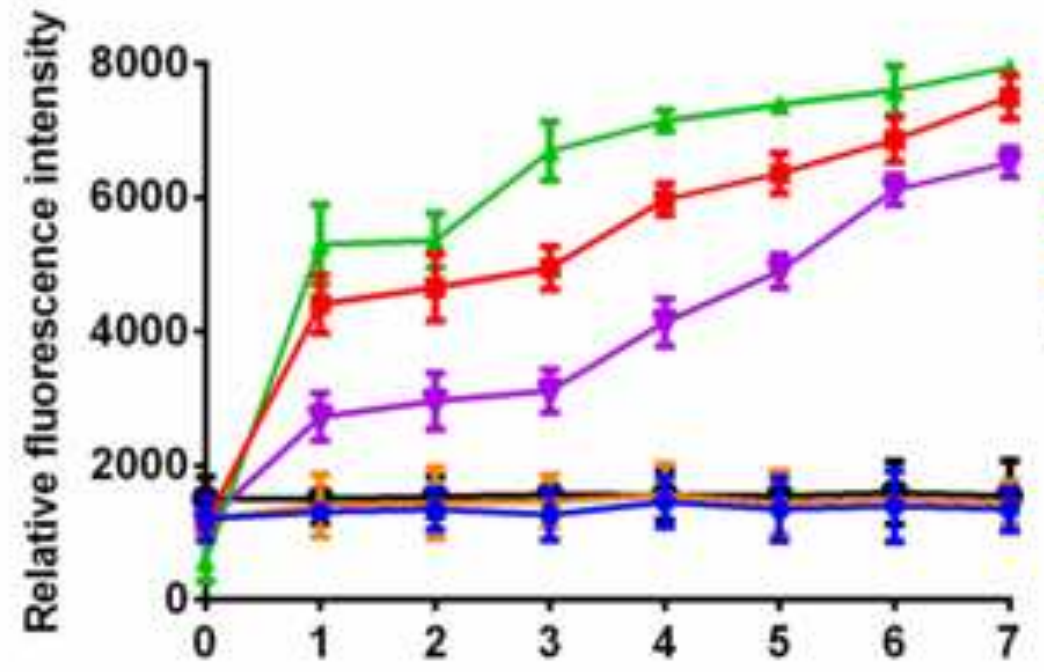

Time (minutes)

C

- Control negative

- P14KanS 5X MIC

- P14KanS10X MIC

- Colistin 10X MIC

- Kanamycin $100 \mu \mathrm{M}$

- P14LRR 10X MiC

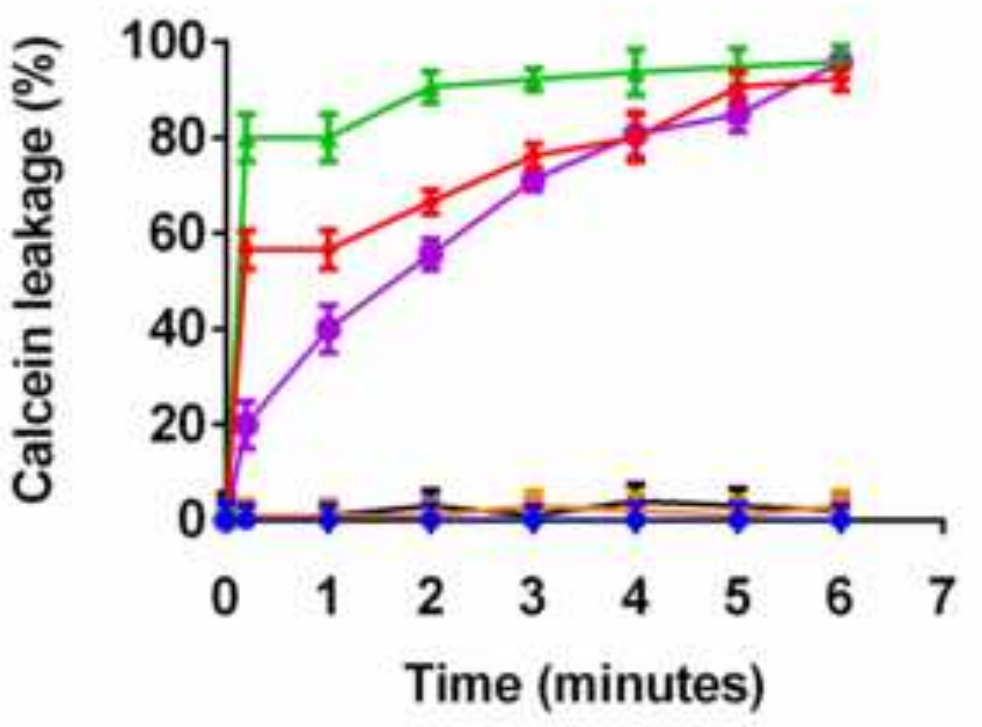

- Control negative

- P14KanS 5X MIC

- P14KanS 10XMIC

- Nisin 10X MIC

- Kanamycin $100 \mu \mathrm{M}$

* P14LRR 10X MIC

P14KanS 5X MIC

- Colistin 10X MIC

Kanamycin $100 \mu \mathrm{M}$

- P14LRR 10X MIC 
A- Logarithmic phase of S. aureus

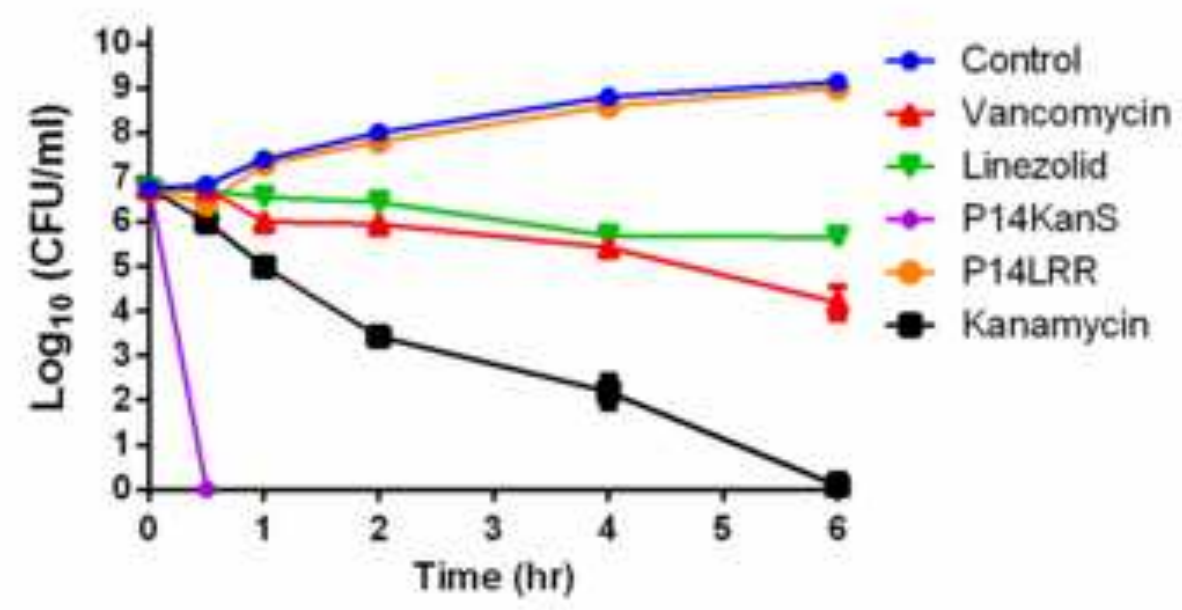

C- Stationary phase of S. aureus

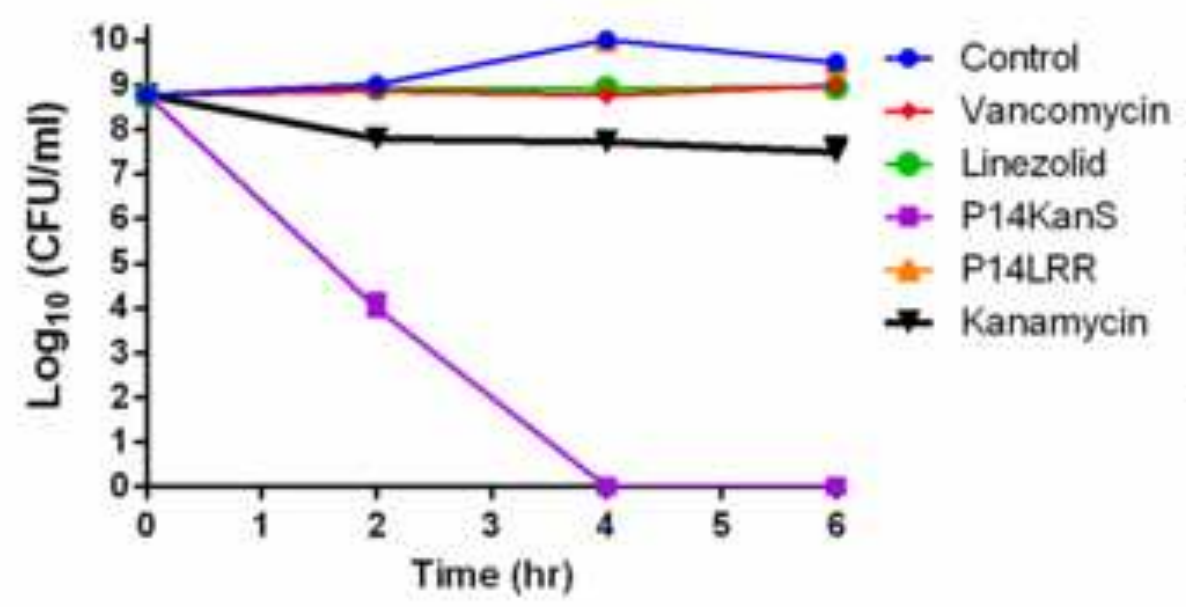

B- Logarithmic phase of S. epidermidis

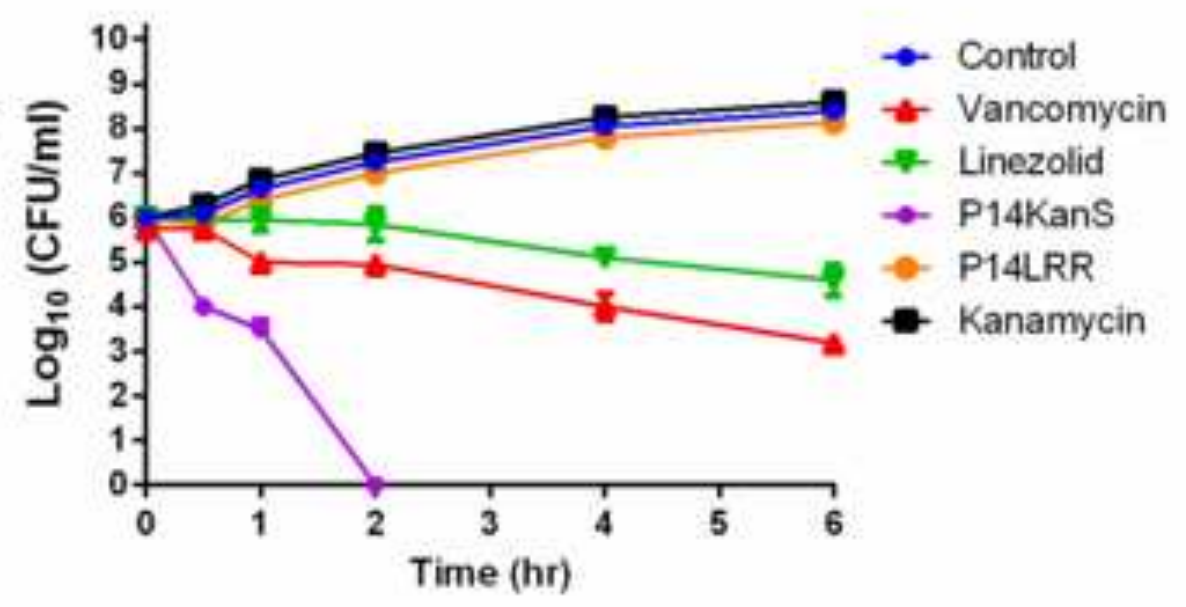

D- Stationary phase of S. epidermidis

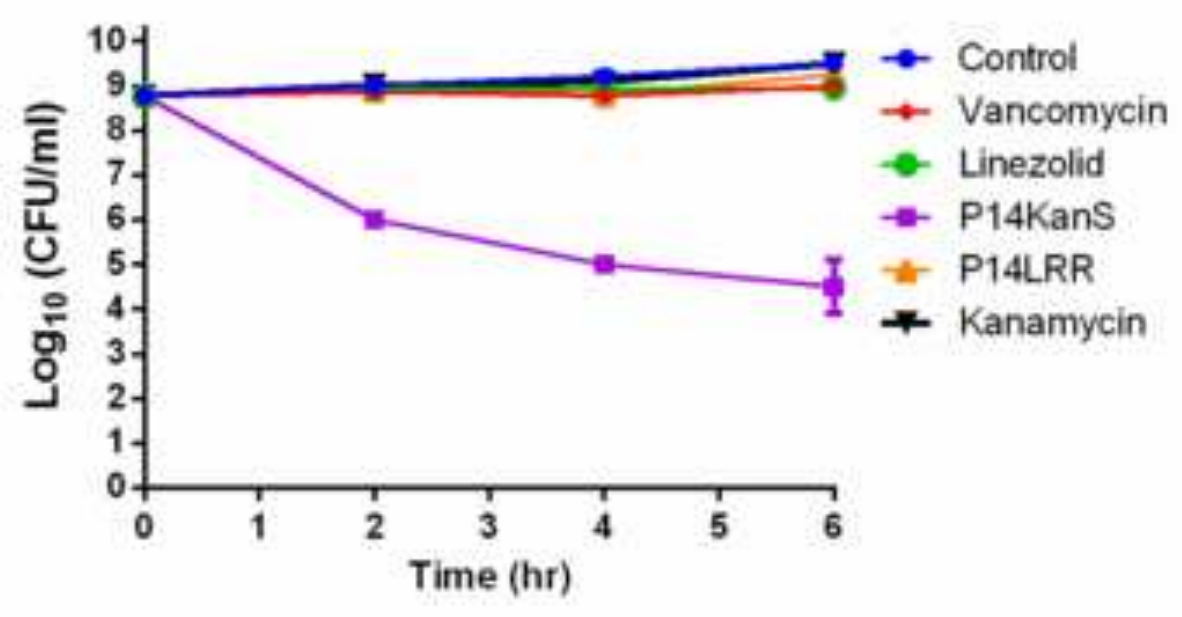


A-Logarithmic phase of $P$. aeruginosa

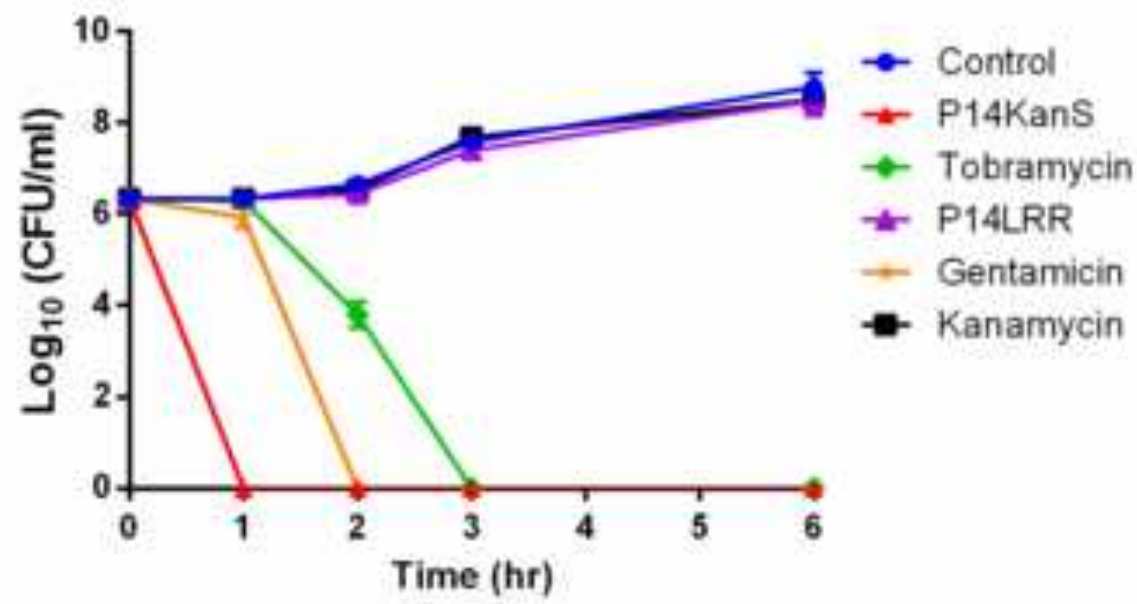

C- Stationary phase of $P$. aeruginosa

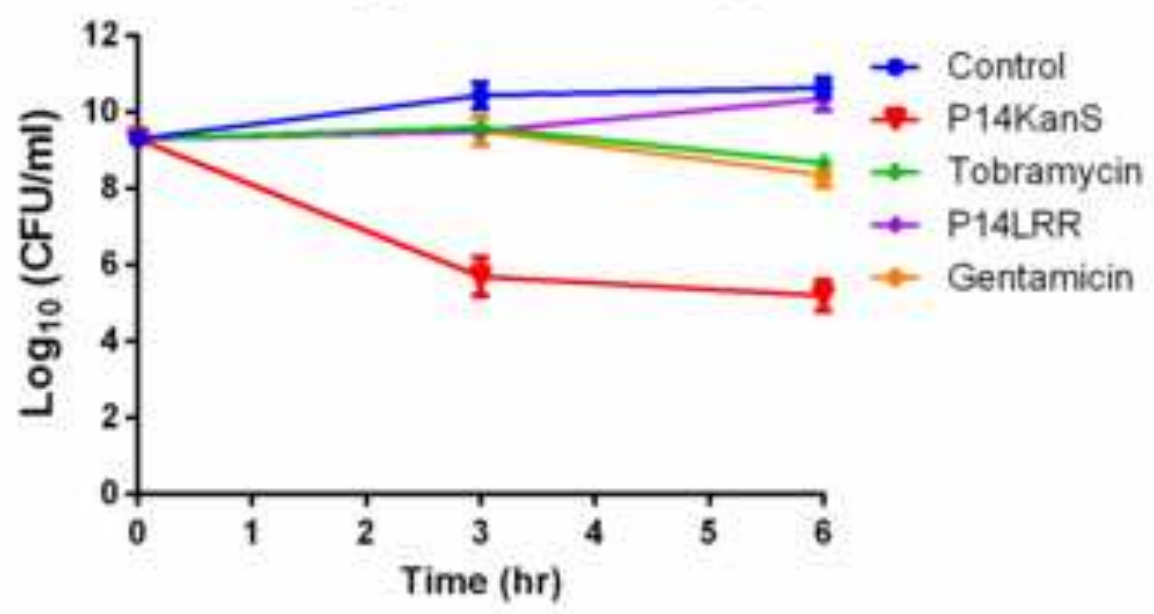

B-Logarithmic phase of $A$. baumanii

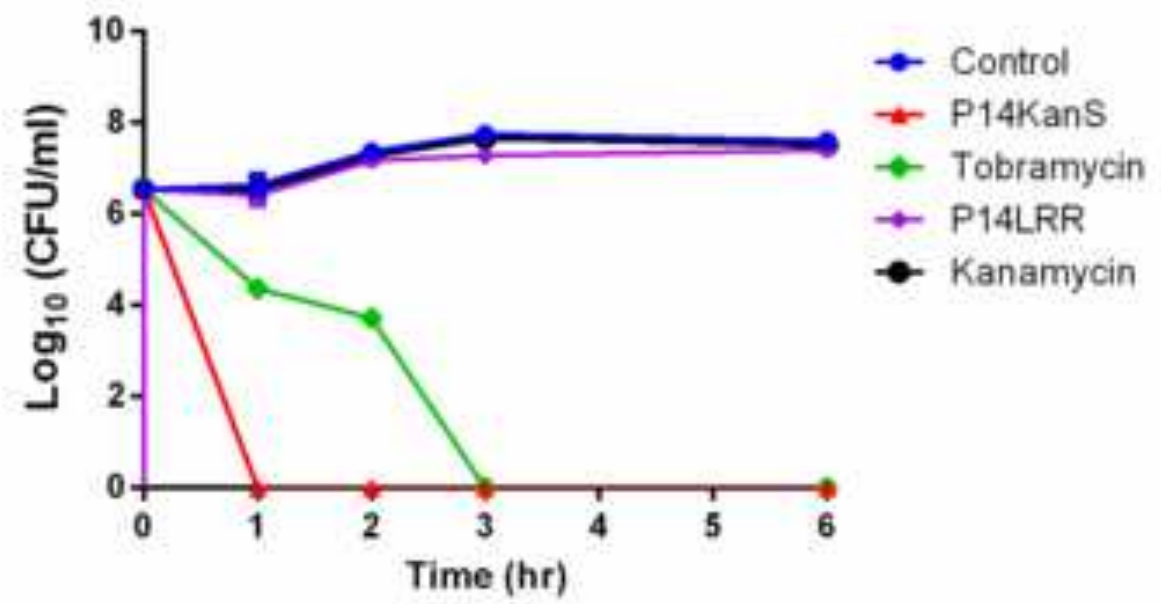

D- Stationary phase of A. baumanii

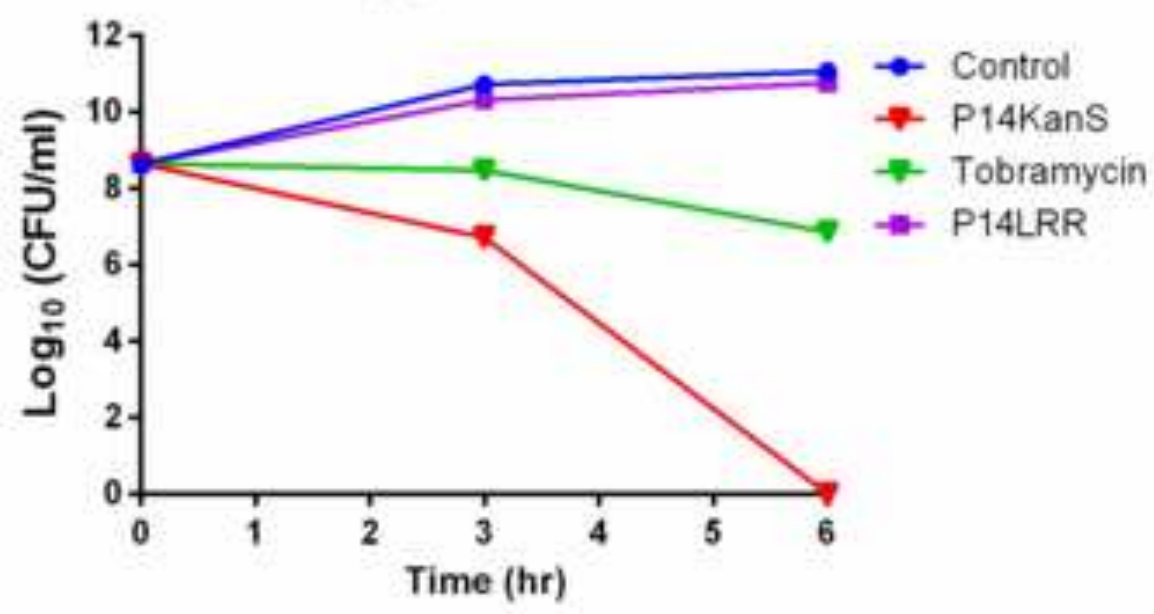


Figure 5
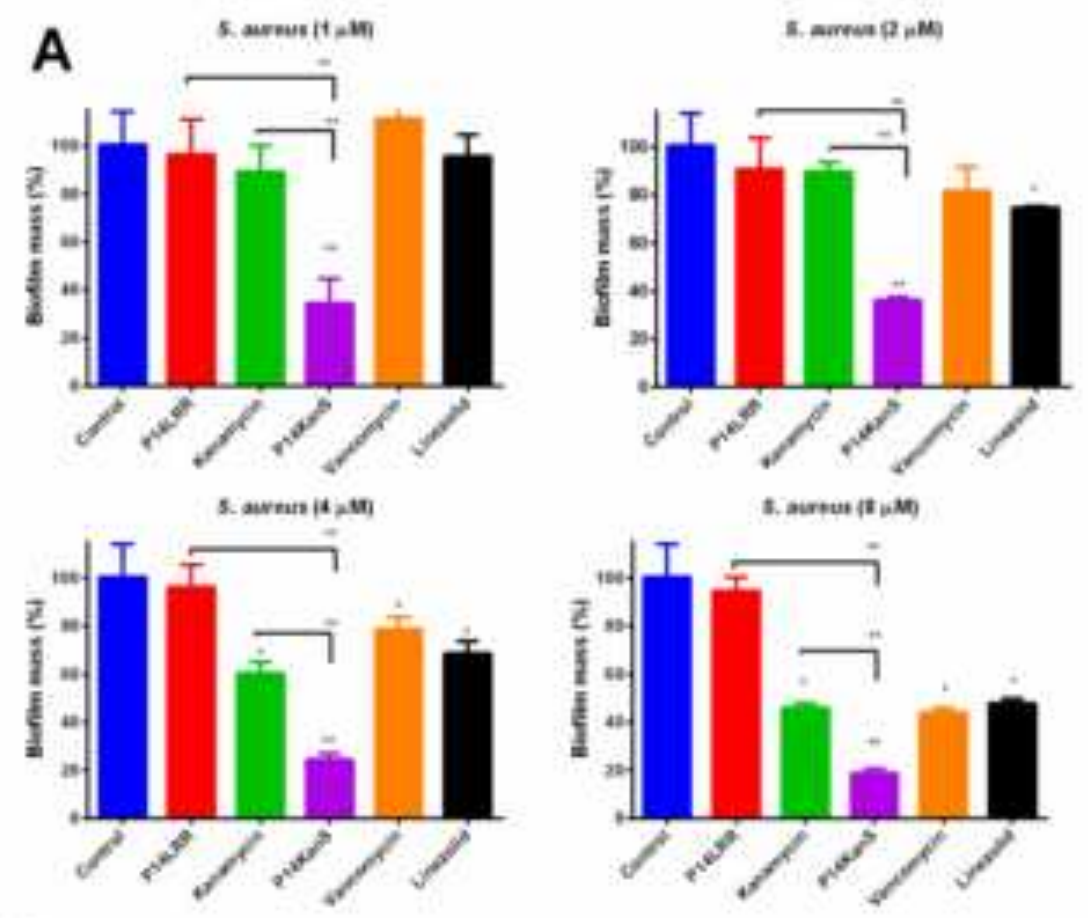

B
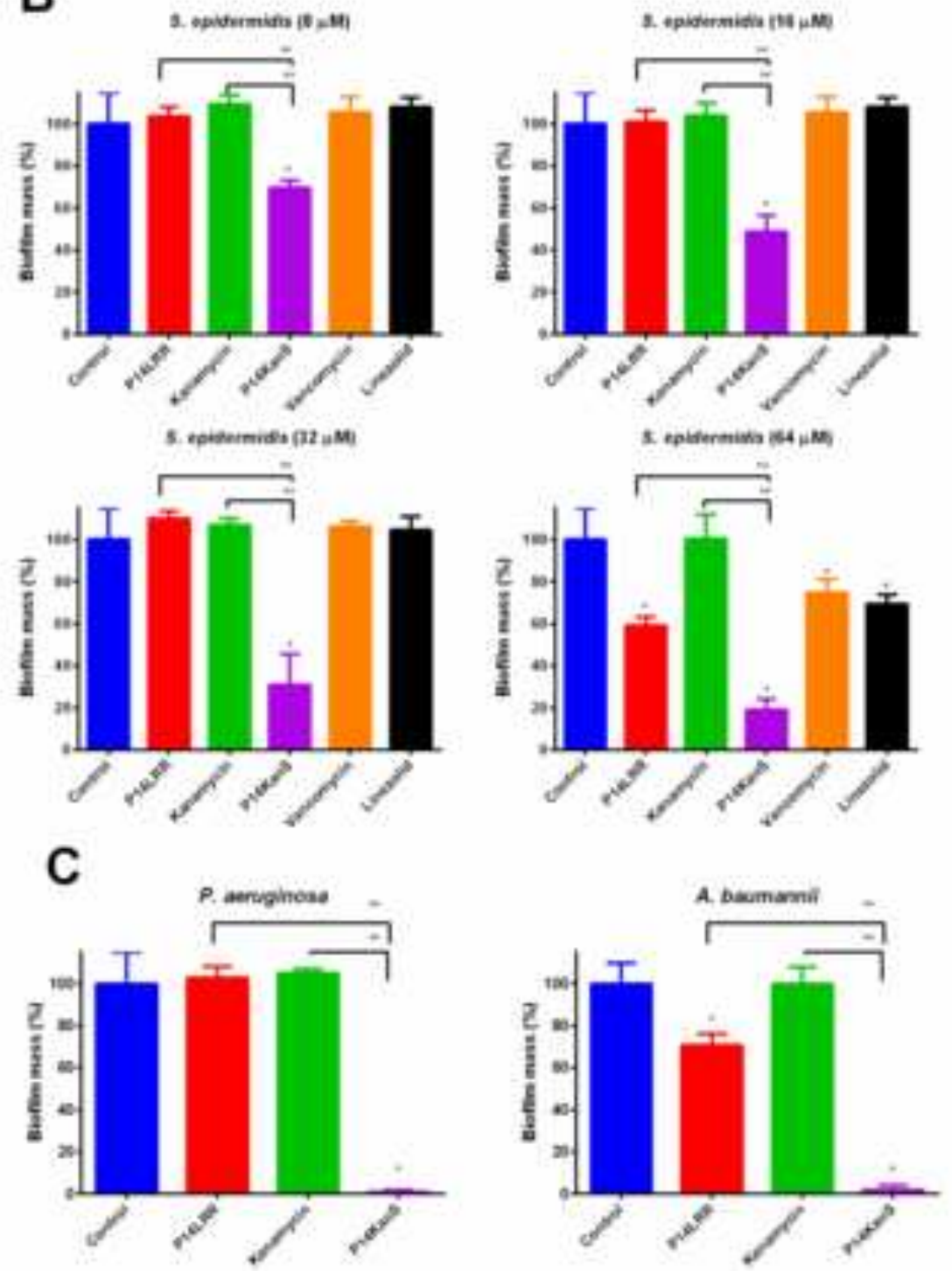
A

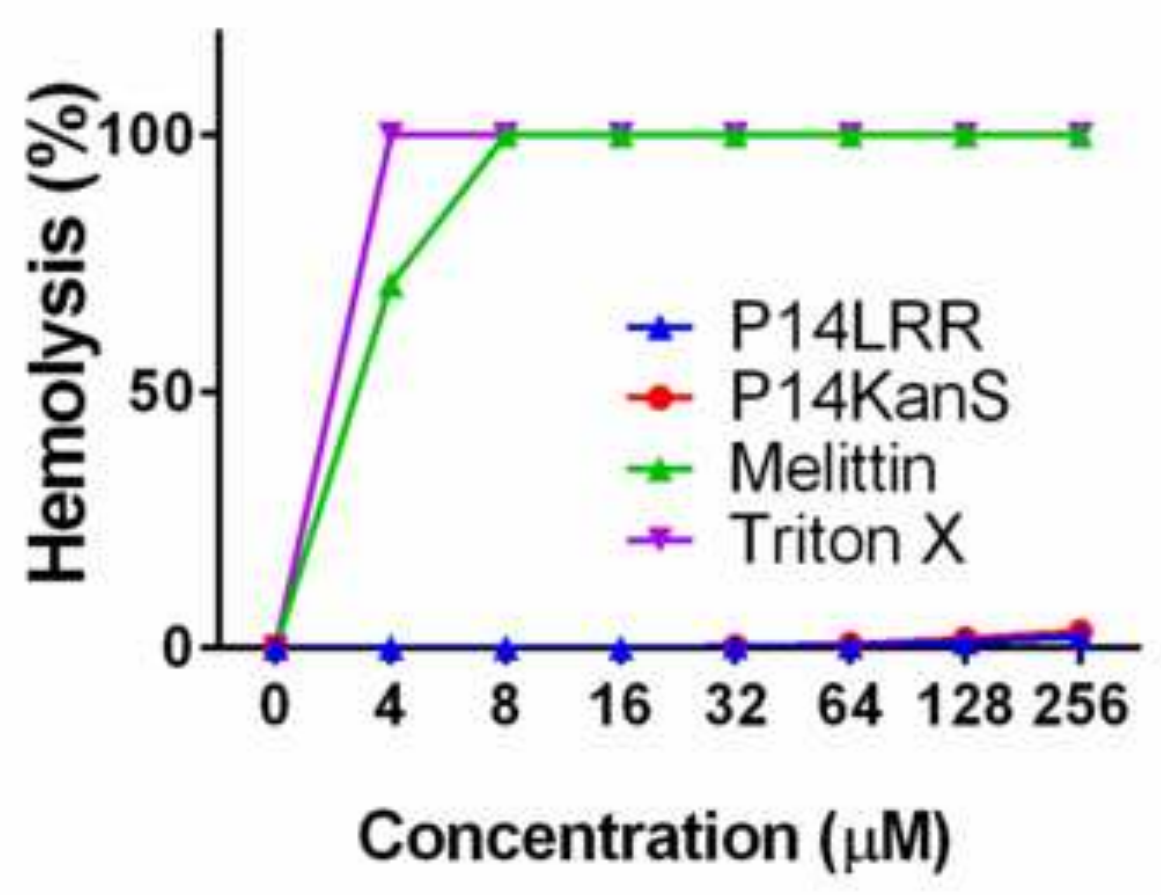

B

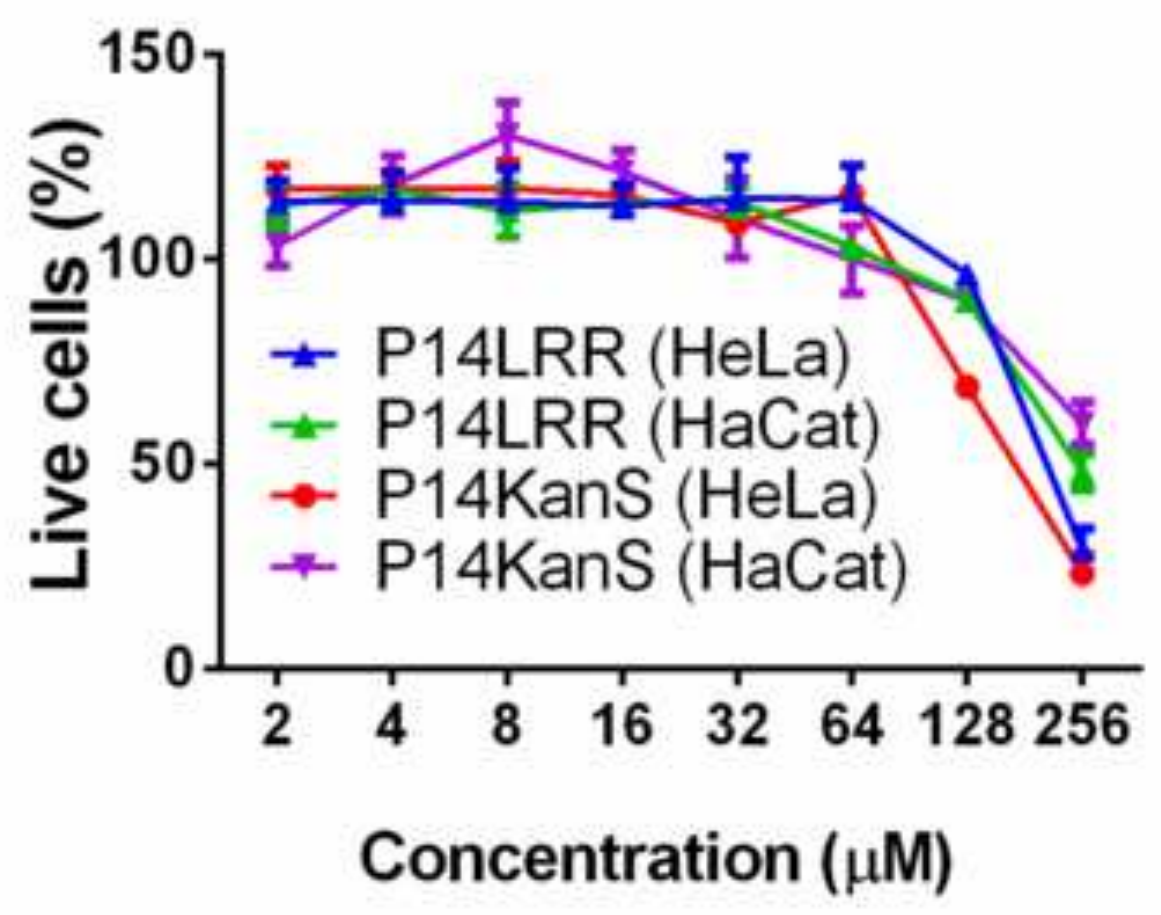


S. aureus ATCC 6538

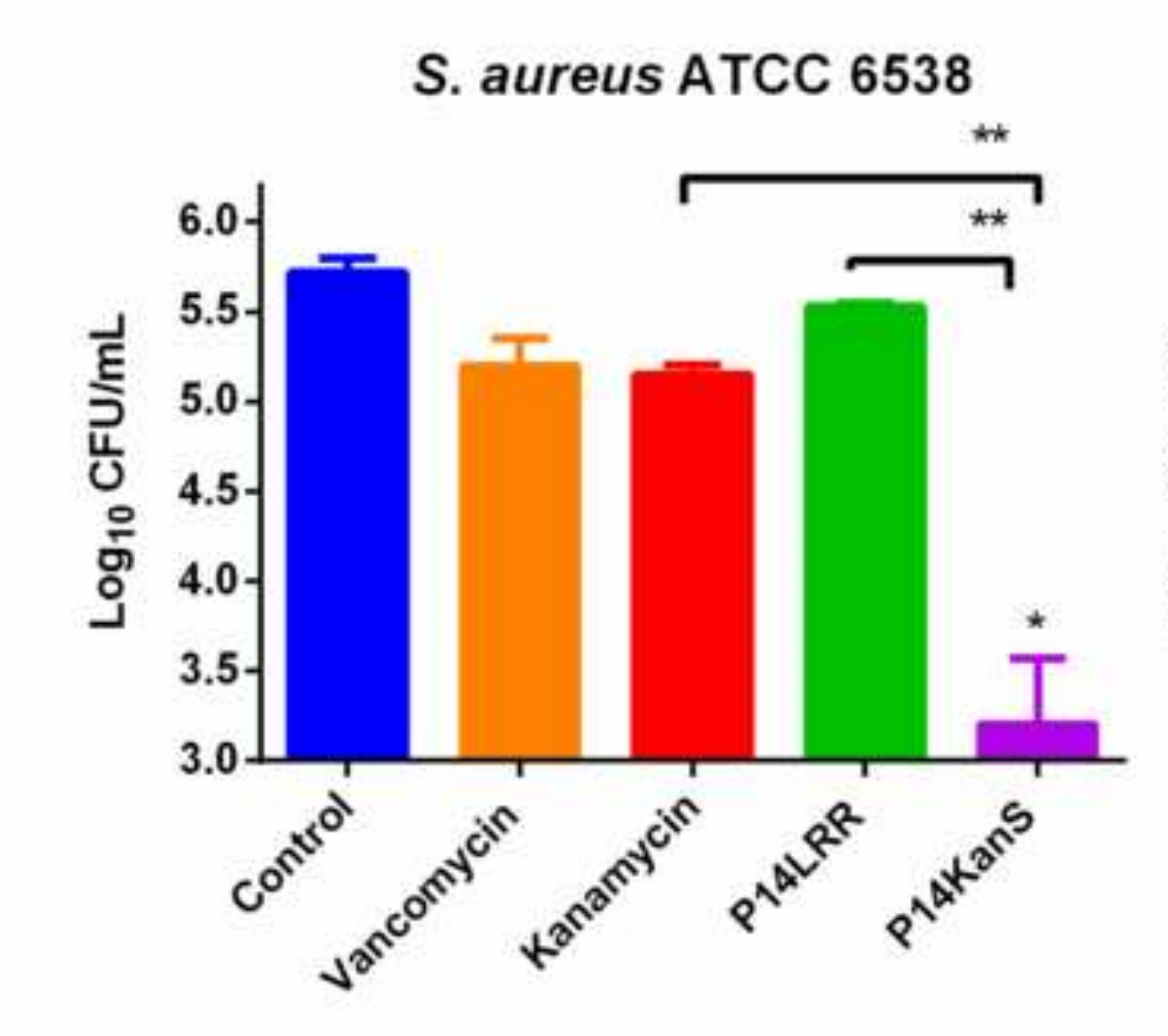

MRSA USA400

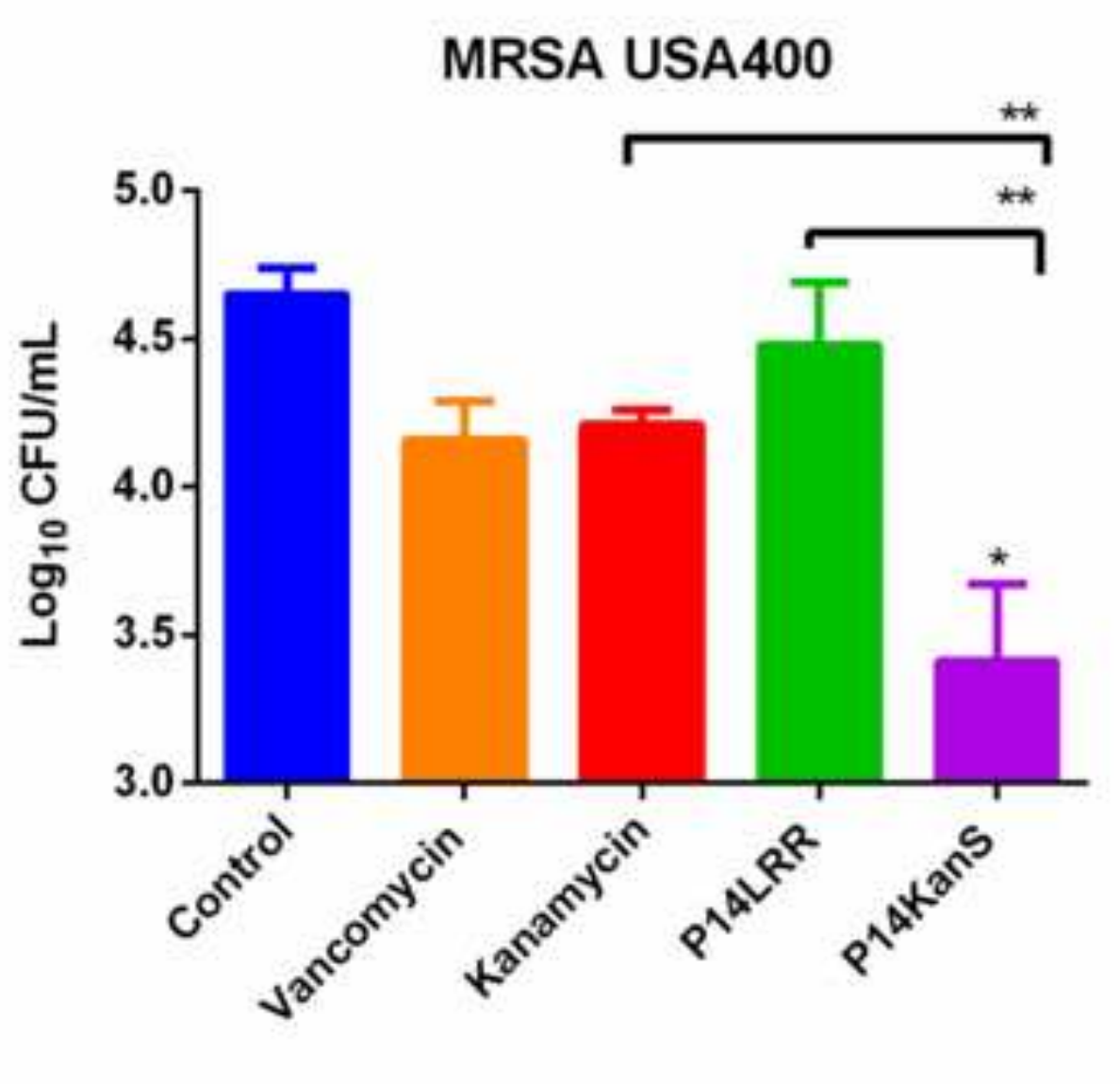

(

政 
A

\section{LPS binding}

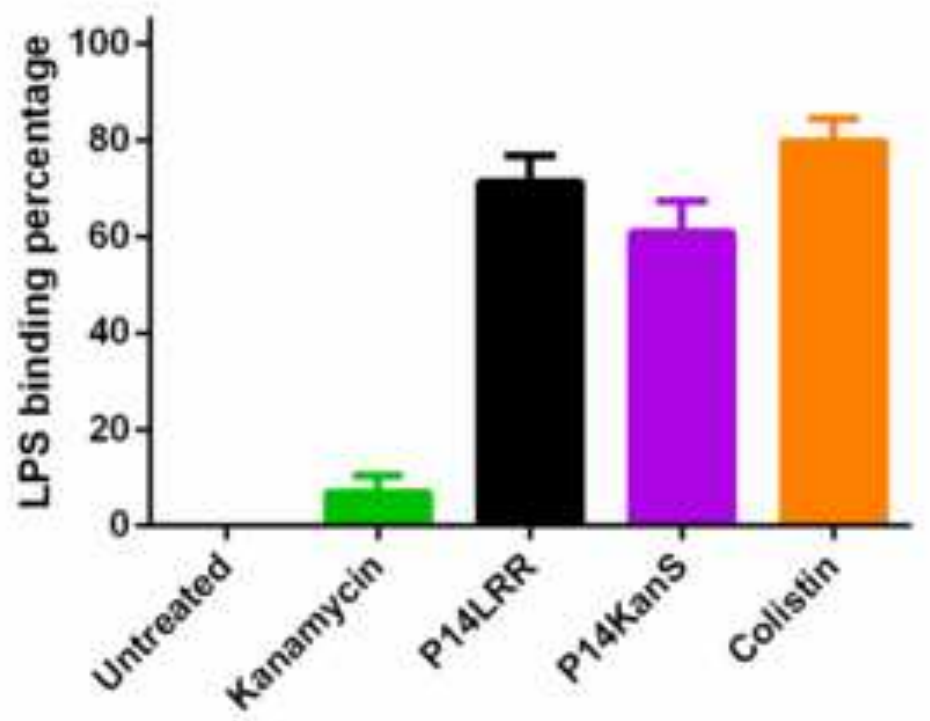

B

TNF $-\alpha$
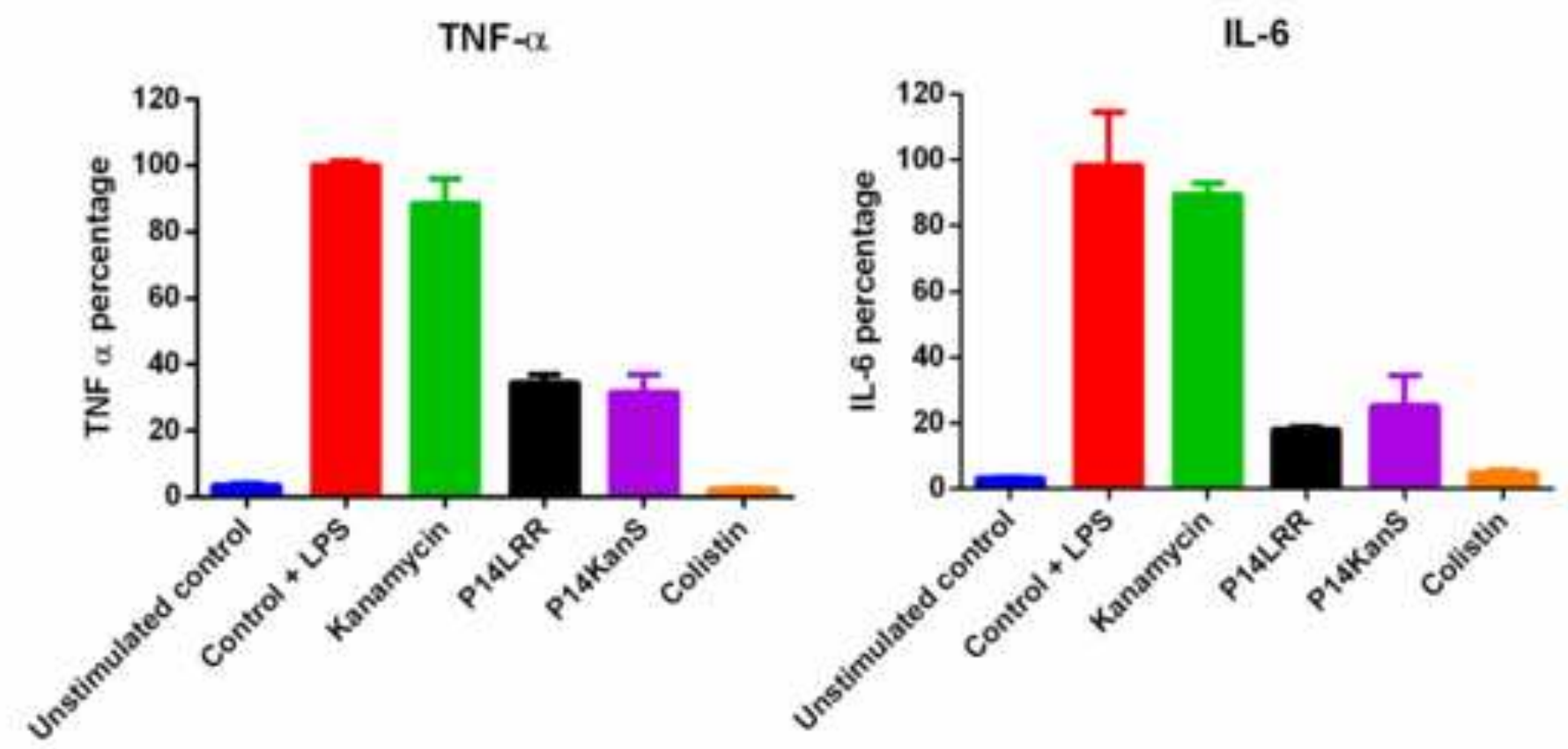

IL-6 


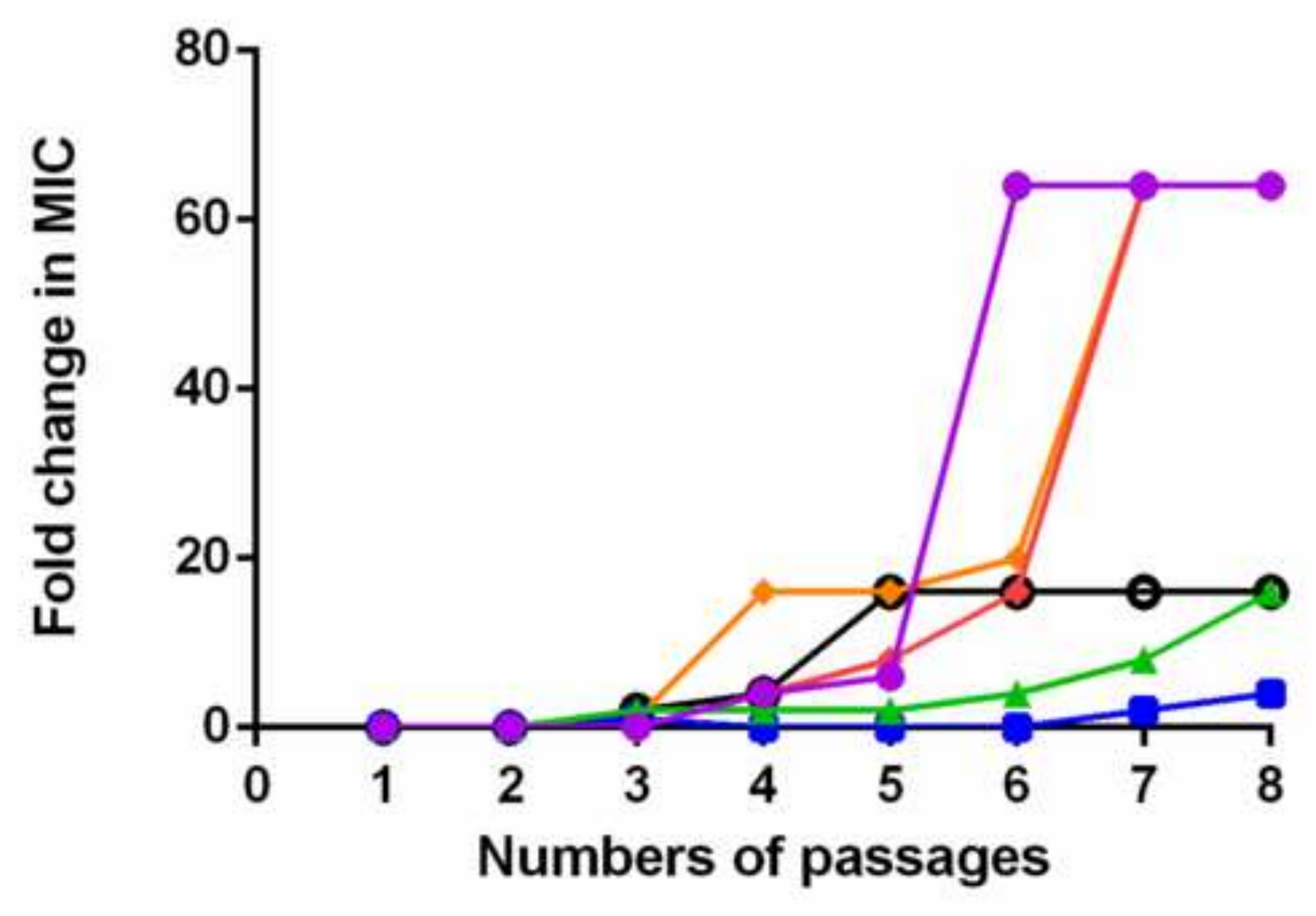

$\rightarrow$ Ampicillin

$\rightarrow$ Kanamycin

- P14LRR

- P14Kans

$\rightarrow$ Rifampicin

- Ciprofloxacin 

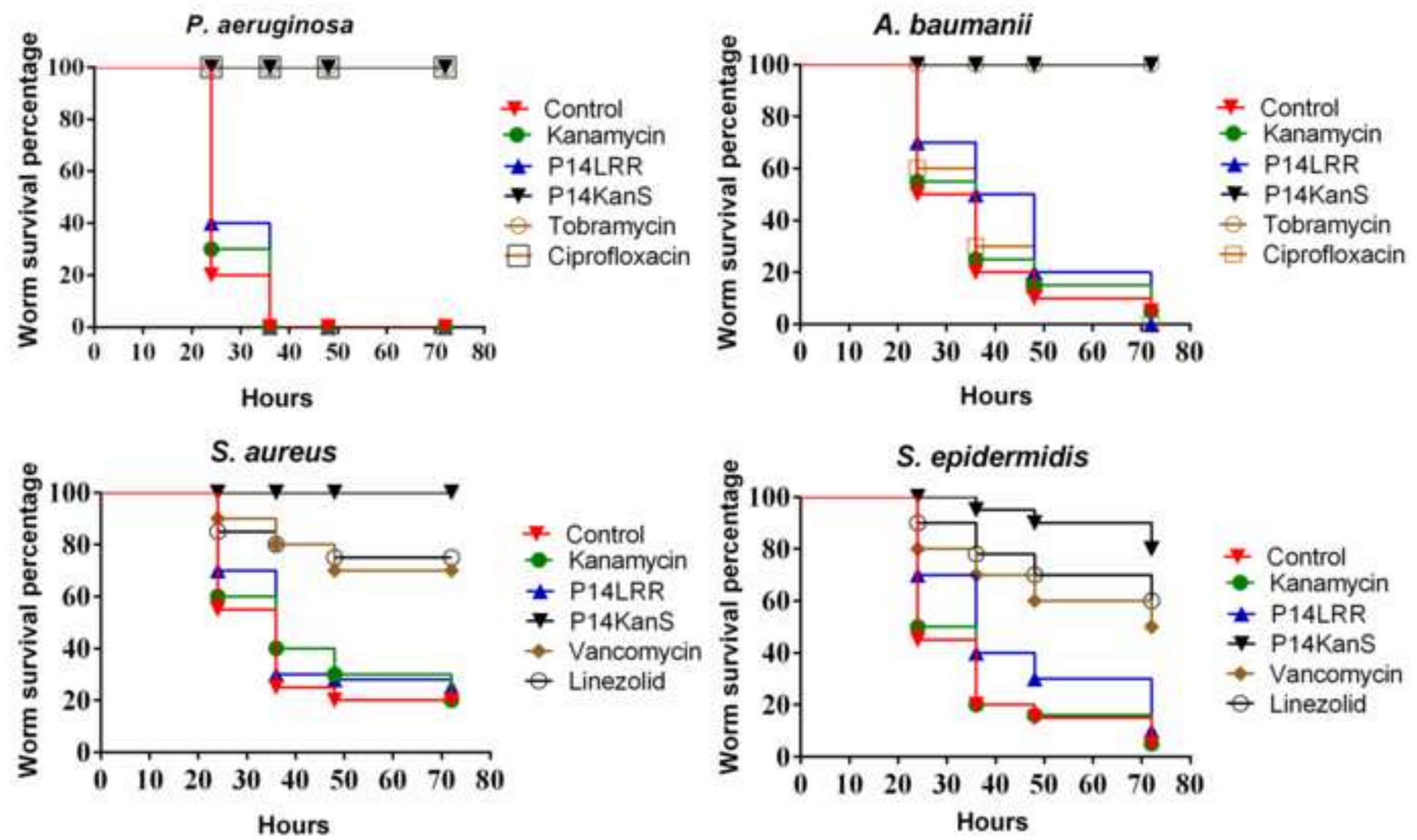